NBER WORKING PAPER SERIES

\title{
IS BLINDED REVIEW ENOUGH? HOW GENDERED OUTCOMES ARISE EVEN UNDER ANONYMOUS EVALUATION
}

\author{
Julian Kolev \\ Yuly Fuentes-Medel \\ Fiona Murray \\ Working Paper 25759 \\ http://www.nber.org/papers/w25759 \\ NATIONAL BUREAU OF ECONOMIC RESEARCH \\ 1050 Massachusetts Avenue \\ Cambridge, MA 02138 \\ April 2019
}

We are grateful to the Bill and Melinda Gates Foundation for providing access to their internal data and procedures, and for their overall support. We thank Cecilia Testart Pacheco for her invaluable assistance with the text analysis portion of the paper. We also thank Pierre Azoulay, Scott Stern, Philippe Aghion, Ray Reagans, Michael Cima, Joshua Krieger, Daniel Fehder, Michael Bikard, Annamaria Conti, seminar participants at MIT and NBER, and conference attendees at the Academy of Management, the American Economic Association, and the REER conference for their helpful comments and suggestions. The views expressed herein are those of the authors and do not necessarily reflect the views of the National Bureau of Economic Research.

NBER working papers are circulated for discussion and comment purposes. They have not been peer-reviewed or been subject to the review by the NBER Board of Directors that accompanies official NBER publications.

(C) 2019 by Julian Kolev, Yuly Fuentes-Medel, and Fiona Murray. All rights reserved. Short sections of text, not to exceed two paragraphs, may be quoted without explicit permission provided that full credit, including $(\odot)$ notice, is given to the source. 
Is Blinded Review Enough? How Gendered Outcomes Arise Even Under Anonymous Evaluation Julian Kolev, Yuly Fuentes-Medel, and Fiona Murray

NBER Working Paper No. 25759

April 2019

JEL No. D70,J16,M14,O31,O32

\begin{abstract}
For organizations focused on scientific research and innovation, workforce diversity is a key driver of success. Blinded review is an increasingly popular approach to reducing bias and increasing diversity in the selection of people and projects, yet its effectiveness is not fully understood. We explore the impact of blinded review on gender inclusion in a unique setting: innovative research grant proposals submitted to the Gates Foundation from 2008-2017. Despite blinded review, female applicants receive significantly lower scores, which cannot be explained by reviewer characteristics, proposal topics, or ex-ante measures of applicant quality. By contrast, the gender score gap is no longer significant after controlling for text-based measures of proposals' titles and descriptions. Specifically, we find strong gender differences in the usage of broad and narrow words, suggesting that differing communication styles are a key driver of the gender score gap. Importantly, the text-based measures that predict higher reviewer scores do not also predict higher ex-post innovative performance. Instead, female applicants exhibit a greater response in follow-on scientific output after an accepted proposal, relative to male applicants. Our results reveal that gender differences in writing and communication are a significant contributor to gender disparities in the evaluation of science and innovation.
\end{abstract}

Julian Kolev

Dept. of Strategy and Entrepreneurship

SMU Cox School of Business

6212 Bishop Blvd

Dallas, TX 75275

jkolev@smu.edu

Yuly Fuentes-Medel

yuly@yfuentes-medel.com
Fiona Murray

MIT Sloan School of Management

100 Main Street, E62-470

Cambridge, MA 02142

and NBER

fmurray@mit.edu

A data appendix is available at http://www.nber.org/data-appendix/w25759 


\section{Introduction}

Diversity and inclusion are key goals for society at large and specifically within the scientific and innovative communities across corporate, government, and academic organizations (Robinson and Dechant 1997, Bilimoria et al 2008, Østergaard et al 2011). Diversity of individuals and ideas leads to better outcomes (Azoulay et al 2011) and higher levels of productivity (Reagans and Zuckerman 2001). This is particularly important in the context of innovation-driven organizations: in such contexts, diversity offers not only the usual benefits of greater efficiency as bias is eliminated, but also the potential to improve an organization's innovative capacity as individuals and teams benefit from the introduction of new ideas and perspectives (Tasheva and Hillman 2018). At the core of any attempt to increase diversity and inclusion lies the selection of projects and people, which are the building blocks for any dimension of diversity. Organizations pursing these goals must decide how best to structure their internal processes in such a way as to ensure diversity and inclusion at all stages of selection - hiring (Fernandez and Fernandez-Mateo 2006), promotion (Castilla and Benard 2010), and resource allocation (Boudreau et al 2016).

Organizations seek to design processes that maximize the selection of the best individuals, teams and ideas, while minimizing opportunities for biased evaluation (especially bias based on ascriptive characteristics). A wide range of approaches exist for improving selection: organizations and individuals have generated superior outcomes by emphasizing objective measures of candidates' ability and past performance (Reuben et al 2014), building institutional support for equality (Monroe et al 2008), mitigating the impact of differences in professional networks (Wold and Wenneras 2010), increasing the diversity of evaluators (Kunze and Miller 2017), and adopting accountability and transparency procedures (Castilla 2015).

While the above approaches are beneficial, they usually fall short of fully eliminating biased evaluation. By contrast, within a variety of settings, blinded review has often been considered as 
the 'gold-standard' process to remove opportunities for bias in evaluation and selection. In the emerging literature on "blinded-ness", more diverse outcomes have been predicated on the notion that differences typically emerge from patterns of bias that can be identified from names (on CVs or scripts, as in McIntyre et al 1980), or in person (musical auditions in Goldin and Rouse 2000, entrepreneurial pitches in Brooks et al 2014); the introduction of blinded review can lead to a significant increase in diversity and inclusion (Goldin and Rouse 2000). However, within the scientific community - the community which pioneered double-blinded review as a central process used to eliminate the role of biased perception in its own activities - evidence suggests that many organizational practices do not in fact lead to unbiased evaluations (Shen et al 2013, Witteman et al 2017). In light of this discrepancy, it is worth considering the impact of blinded review in the context of innovation and scientific activity, as it seems to be a necessary condition for the elimination of bias. We attempt to evaluate whether blinded review is sufficient to overcome all aspects of under-representation, or whether there are significant barriers to diversity that remain after its implementation.

Our paper explores the degree to which gender shapes outcomes even in a blinded setting, and seeks to evaluate the drivers of gender disparity in science and innovation, in terms of both access to key inputs and subsequent output. We take advantage of data covering a blinded grant-review process from the Bill and Melinda Gates Foundation that has several critical characteristics: reviewers evaluate anonymous proposals, the reviewing process enables multiple individual reviewers to provide independent scores, it provides scoring data at the reviewer-proposal level, and it allows us to trace individual applicants' later activities through scientific publications, NIH grant receipts, and other measures of innovation.

Using a sample of 6,794 proposals submitted to the Gates Foundation between 2008 and 2017, we analyze two major components of the interplay between diversity and innovation. First, we 
examine the determinants of diversity in innovative organizations, by examining the role of gender in explaining reviewer evaluations of innovative proposals. Second, we construct a difference-indifference estimator to explore the interaction between funding and applicant gender, in order to identify the differential impact of funding across applicants. In these analyses, we focus on a homogeneous sample of US-based life science researchers, and take advantage of the features of our setting to identify the causal impact of gender on both reviewer scores and subsequent outcomes.

Our results offer important new insights into the relationship between diversity and innovation. We find that even in an anonymous review process, there is a robust negative relationship between female applicants and the scores assigned by reviewers. This disparity persists even after controlling for proposal topics, reviewer demographics, applicant publication histories, and applicants' prior applications. However, the gender disparity becomes insignificant after controlling for text-based measures of applicants' proposals. Specifically, building on the text analysis methods of previous studies (Schmader et al 2007, Kaatz et al 2015), we show that female applicants use fewer of the words favored by reviewers when describing their proposals, and more of the words associated with low reviewer scores. Exploring this pattern further, we show that female applicants have a tendency to choose more "narrow" (i.e. topic-specific), words and fewer "broad" words. Both of these tendencies lead to lower scores for female applicants, with their use of narrow words having the greater negative effect. After controlling for the impact of word choice, the gender-based score disparity is no longer significant, and its effect size drops by over $50 \%$. Our findings therefore suggest that a focus on writing style and word choice can offer mechanisms through which innovative organizations may seek to improve their evaluation and selection processes. 
Having shown how communication style influences the evaluation of innovative proposals, we then turn our attention to follow-on innovative outcomes. Specifically, we explore how male and female applicants differ in their innovative output subsequent to their application, across measures such as academic publications and NIH grant awards. We begin by establishing that the text-based measures which were a major driver of selection by (blinded) reviewers do not also predict an increase in follow-on innovation. Most prominently, we show that the use of the broad words favored by reviewers actually predict a decrease in ex-post outcomes, suggesting that reviewers may be overly credulous to broad descriptions that are likely to reflect style more than substance. Next, we find that across a range of outcomes, being selected by the Gates Foundation leads to a bigger impact for female applicants, primarily through "leveling the playing field" relative to male applicants. Specifically, female applicants are disadvantaged relative to male applicants if they are not selected; by contrast, successful female applicants generate innovative outcomes that are either indistinguishable from or better than those of successful male applicants. Indeed, the disappearance of disparities after being selected and receiving Gates Foundation funding suggests that from the perspective of impact, female applicants may well generate a greater "return" on Gates Foundation resources. This effect is strongest for the outcome of NIH grant funding, where successful female applicants not only catch up but significantly outperform their male counterparts.

Overall, our results identify two major areas where gender and innovation interact: first, the choice of (excessively narrow) words by female applicants to describe their innovations can lead to a significant reduction in their perceived quality (even when the proposed innovations are actually high-quality!). Second, the failure to be selected for funding acts as a disproportionate barrier to the follow-on innovation of female applicants, while successful female applicants exhibit outcomes that are either indistinguishable from or superior to those of their male counterparts. 
These findings suggest that there is significant scope for improvement at innovation-driven organizations, in terms of both increasing the selection of high-quality projects, and allocating resources to the innovators for whom they would have the greatest impact.

\section{Diversity, Gender, and Innovation}

\section{A. Definitions: Diversity, Innovation, Efficiency, and Bias}

Diversity and Innovation: In this paper, we approach the topic of organizational diversity by focusing on just one of its many dimensions, namely, gender. While our analysis is on the level of individuals, our findings on gender disparities can lead to increased diversity for any organization where women are underrepresented. Indeed, this pattern exists for many knowledge-based organizations, including our own empirical setting. In addition to identifying mechanisms that increase diversity by expanding the inclusion of women in such organizations, we also seek to estimate the impact of gender on innovative output. We measure innovation through a combination of proposal-based metrics, article publications, and NIH grant awards. We also perform text-based analysis using Medical Subject Heading (MeSH) terms in order to capture the direction of innovation as well as its quantity and quality.

Equity, Equality, and Efficiency: It is important to differentiate between equity, equality, and efficiency. The concept of equity is referenced most often in aid-focused organizations, which tend to pursue the goal sending the most resources to places with the highest needs, e.g. by helping eradicate malaria in Africa. Importantly, this is in contrast to the goal of equality, which would dictate a similar level of resource allocation to all regions and projects, irrespective of need. Finally, both equality and equity are distinct from efficiency, which is defined as allocating resources to the most productive or promising projects, even if those projects do not necessarily line up with the areas of greatest need. In most cases, a balance of both equity and efficiency is required for an organization to effectively impact its priorities. In the case of the Gates Foundation, 
the main target of impact is the quality of life of disadvantaged groups, with a particular focus on health and infectious diseases in our sample. We measure progress toward these goals by tracking the publications and grants that result from the Gates Foundation's funding decisions.

Bias and Demographic Disparity: We take our definition of bias from Poppenhaeger (2017):

The definition of bias is a positive or negative unconscious belief about a particular category of people. This allows quick, but sometimes inaccurate, processing of information...Biases are not the same as discrimination; discrimination can happen if a person actually acts on their biases...If biases go unchecked, they can have multiple detrimental effects for groups against which negative biases exist, for example in performance evaluations, hiring, and career progression.

Importantly, this definition highlights the fact that evaluators may be unaware of any potential bias they possess. Prior work indicates that bias can interact with structural elements of organizations (Murray and Graham 2007, Kelly et al 2010, Ding, Murray, and Stuart 2012) to generate significant disparities in outcomes across demographic groups. If such bias-driven mechanisms are the dominant driver of organizational demographics, one might expect that the adoption of double-blind evaluations would suffice to overcome both explicit and implicit bias, and lead to greater inclusion for women and other under-represented groups. However, bias, either explicit or implicit, may not be the sole driver of demographic disparities. Differences in interests, experience, risk tolerance, or other factors may generate a disparity across demographic groups, even under a completely unbiased review process. Thus, while organizations should certainly aim to remove bias from their evaluations, this may not be sufficient if their goal is to eliminate the demographic disparities that have limited their diversity.

\section{B. Diversity in Knowledge-Based Organizations}

A number of recent studies have focused on the under-representation of women, racial minorities, and other demographic groups in innovative fields (Cook and Kongcharoen 2010, Lincoln et al 2012, Bell et al 2017, Marschke et al 2018) and knowledge-based organizations (Fernandez and Campero 2014, Gompers and Wang 2017). The academic attention has been complemented by 
discussion of workforce diversity in the popular press, leading top technology companies like Google and Apple to begin disclosing the demographic statistics of their employees. While such reports can spur greater awareness of the lack of diversity in knowledge-based organizations, these group-level statistics do not offer an opportunity to identify the mechanisms behind the patterns of diversity, because they do not capture outcomes at the individual level. By adopting the perspective of individual innovators, we add to the growing literature seeking to track the presence and impact of demographic disparities over the course of individuals' entire careers (McKown and Weinstein 2002, Hengel 2017, Lerchenmueller and Sorenson 2018).

\section{The Structure of Gender Disparity and its Potential Drivers}

The structure of gender disparities has been the subject of considerable recent research, spanning a wide range of contexts. Some studies have focused on direct mechanisms such as bias and discrimination, where it is possible to observe that an individual belongs to a disfavored group (Castilla 2008, Brooks et al 2014, Cook et al 2018), and this leads to a disparity in outcomes. This stands in contrast to studies focusing on indirect mechanisms, where a disparity in outcomes exists despite the lack of direct discrimination (Ginther et al 2016, Fernandez and Campero 2017). In this latter group, disparities can be driven by self-selection, conforming to stereotypes, or avoidance of competition, rather than the direct impact of ascriptive bias. Our own focus is on this latter form of disparity: we are able to exclude the role of bias thanks to the blinded review process used in our empirical setting. This allows us to not only estimate the magnitude of the gender disparities that persist after eliminating traditional forms of bias and discrimination, but also to highlight the precise mechanisms which drive any remaining gender disparities. Indeed, our setting is meant to complement the approach described by Goldin and Rouse (2000), who show that anonymous applications are sufficient to significantly reduce disparities faced by female musicians in symphony orchestras. By contrast, in our setting, significant differences in outcomes persist even 
under an anonymous evaluation process, suggesting the need for further analysis of the indirect drivers of gender disparity.

\section{The Interaction of Demography and Innovation}

Innovation is a particularly challenging context for demographic diversity and inclusiveness: unlike other fields, it has a number of features which make it difficult for standard efficiency-based effects to push out discriminatory tendencies. ${ }^{2}$ Specifically, the following features of innovation make it more likely than other fields to harbor a persistent lack of diversity:

- Outcomes are unpredictable, and there are long lags before success is realized

- Outcomes are only observable for funded or attempted innovations

- An individual's contribution is hard to separate, esp. in cumulative innovation

- Teamwork is often required to push past the current state of the art, and some team members might prefer working with those similar to them

These challenges are significant, and innovative fields do often generate greater disparities than other sectors (Magua et al 2017). At the same time, diversity, while lacking, may be uniquely valuable in the context of innovation (Robinson and Dechant 1997, Østergaard et al 2011). Innovative organizations would stand to gain not only the usual efficiency benefits from a reduction in discrimination, but they would also have the potential to introduce new ideas, or recombine existing ideas in new ways. We therefore seek to evaluate both sides of this question in our context, as we focus specifically on the dimension of gender: what mechanisms can lead innovative organizations to become more diverse, and what are the potential benefits of such an increase in diversity?

\section{Data and Methods}

\footnotetext{
${ }^{2}$ For a full discussion of the traditional perspective on discrimination and (in)efficiency, see Becker (2010).
} 


\section{A. Empirical Strategy and Regression Specifications}

In analyzing the relationship between gender and innovation-related outcomes, there are a number of challenges that normally interfere with attempts to estimate causal effects. To capture an organization's ability to evaluate innovations, an ideal empirical design would take ideas of comparable ex-ante quality, and randomly assign each idea to multiple applicants across a range of demographic groups. These applicants, also of comparable ex-ante quality, would develop and submit proposals based on the ideas to the organization. If the proposals were submitted anonymously, it would be possible to remove the direct elements of bias and identify any indirect or underlying causes of gender disparity. Ideally, these proposals would then be (independently) evaluated by a diverse set of reviewers, in order to examine the relative impacts of applicant and reviewer demographics. We can approximate this ideal empirical design in our setting by attempting to control for idea and applicant quality while comparing the scores that different reviewers give to a single proposal. Thus, the regression specification we would like to estimate is:

$$
\begin{aligned}
\text { Reviewer_SCore }_{i j k} & \\
& =\beta_{0} X_{i j k}+\beta_{1} \text { ApplicantGender }_{j}+\beta_{2} \text { ReviewerGender }_{k}+\beta_{12} \text { Interaction }_{j k} \\
& +\epsilon_{i j k}
\end{aligned}
$$

In the above equation, we estimate the score of idea $i$, from applicant $j$, as evaluated by reviewer $k$. The vector of covariates $X_{i j k}$ varies by specification, and can include fixed effects for the time of submission and the subject area of the idea, text-based measures of the idea's title and description, and a range of applicant and reviewer characteristics. The demographic variables capture the gender for both applicants $j$ and reviewers $k$, and the interaction term identifies the impact of shared demographic characteristics between applicants and reviewers (e.g. a female reviewer evaluating a proposal from a female applicant). The primary coefficient of interest in these specifications is $\beta_{1}$, the impact of applicant gender on the score received from reviewers; 
specifically, we will track how this coefficient changes based on the inclusion of controls for covariates that might be correlated with both applicant gender and reviewers' evaluations.

Turning to the second portion of our empirical design, we encounter the additional challenge of analyzing the relationship between gender and innovative outcomes. In an ideal research setting, we would like to take a single idea and assign it to "twin" applicants of identical quality and from the same demographic group, and randomly assign funding to one but not the other. We would then want to compare the funded idea with the one that did not receive funding, and perform a difference-in-differences analysis across demographic groups whose ideas also receive the same random assignment of funding. In this context, we approximate this ideal design through a regression-discontinuity approach. Specifically, we compare funded proposals to proposals that received high scores from reviewers but did not receive funding. Our estimated equation becomes:

$$
\begin{aligned}
& \text { InnovativeOutcome }_{i j} \\
& \qquad=\beta_{0} X_{i j}+\beta_{1} \text { Funding }_{i}+\beta_{2} \text { ApplicantGender }_{j}+\beta_{12} \text { Interaction }_{i j}+\epsilon_{i j}
\end{aligned}
$$

In the above equation, we analyze our sample at the level of idea $i$ from applicant $j$, and $X_{i j}$ captures key covariates including fixed effects for the time of submission and the subject area of the idea, as well as key applicant characteristics such as innovative output during the ex-ante period. While the direct effects of funding and applicant gender are valuable for interpreting the overall pattern of results, the primary coefficient of interest is $\beta_{12}$, which captures the differential impact of funding across applicant gender. ${ }^{3}$ In effect, this is a difference-in-differences estimator of the impact of diversity on innovation, and allows us to draw conclusions regarding the efficiency of the innovative process.

\section{B. Empirical Setting: The Gates Foundation's GCE Program}

\footnotetext{
${ }^{3}$ In some specifications, we focus solely on applicants who successfully obtained funding; in this setting, rather than a difference-in-differences approach, we instead draw conclusions from the direct effects of gender on innovative outcomes.
} 
In the previous section, we identified a set of ideal experimental settings that would allow researchers to estimate the impact of diversity on innovation, both in terms of understanding the drivers of diversity in innovative organizations, and in terms of the impact of diversity itself on innovative outcomes. While the expectation of random assignment of funding is not likely to be satisfied in any well-run organization, our empirical setting does offer a number of valuable features that allow us to estimate the relationship between diversity and innovation. Our empirical setting is the Global Challenges: Exploration (GCE) Program at the Bill and Melinda Gates Foundation (subsequently, the Gates Foundation), providing a sample 6,794 anonymous proposals submitted by US-based researchers from 2008-2017. While this program offers valuable internal information on the decisions of individual reviewers, it also differs from more "traditional" grant review institutions (e.g. the NIH or NSF): these organizations use a non-blind review process and send proposals only to reviewers within the proposal's narrow subfield. Further, traditional grantreview institutions often engage in consensus-based collective decisions, where reviewers discuss proposals together and at a collective evaluation representing the views of the entre reviewer panel (NIH 2008). By contrast, the GCE Program implements a review process with the following key characteristics: diverse panels of reviewers, anonymous proposals, and champion-based funding decisions.

- Anonymous proposals - reviewers have no information on the candidate beyond the proposal details

- $\quad$ Diverse pool of reviewers - reviewers are drawn from a wide range of scientific fields and may be from non-academic backgrounds such as the private sector or government

- Independent evaluations - reviewers do not confer with each other when assigning scores 
- "Champion-based" review - rather than relying on consensus across multiple reviewers, strong support from a single reviewer can greatly increase the odds of being funded ${ }^{4}$, while strong negative reviews are treated as identical to neutral reviews

The above features reflect the priorities of the Gates Foundation in its search for solutions to major challenges in global health and development. At the same time, they introduce a richness of variation in both reviewers and proposals, allowing for detailed analysis of reviewer decisions and project outcomes.

\section{Data Sources and Key Variables}

The data for our analysis comes from the first nineteen rounds of the GCE program, which includes a total of 17,311 proposals focused on infectious disease research submitted between 2008 and 2017. In order to ensure a homogeneous pool of applicants, we focus on the 6,794 proposals submitted by applicants who have both an academic or non-profit research affiliation and a US contact address. ${ }^{5}$ These proposals, submitted by 5,058 unique applicants, were allocated across subsets of 132 innovation-panel reviewers, leading to a total of 21,453 reviewer-proposal pairs. From the Gates Foundation, we obtain identifying information on the identities of proposers and reviewers, the substance of the proposals, and the reviewer scores and funding outcomes resulting from the program. We calculate probabilistic measures of gender for both applicants and reviewers using the techniques of Sood and Laohaprapanon (2018). Reviewer evaluations in our sample are simple but highly skewed: from an average portfolio size of over 100 proposals per round, reviewers can choose a single proposal to receive their highest level of support (categorized as a "Gold" rating by the GCE program), and can award up to five other proposals with a high level of

\footnotetext{
${ }^{4}$ While a single reviewer can greatly increase the funding odds for any single project, their highest level of endorsement can only be given to one of the approximately 100 proposals that they review during each round of the program.

${ }^{5}$ In the interest of analyzing a homogeneous sample, we also drop the small fraction applicants that we identify as members of under-represented minorities.
} 
support (categorized as a "Silver" rating). ${ }^{6}$ Our empirical approach employs an ordered-logit specification to capture this decision process. Based on these reviewer evaluations, a total of 635 proposals $(\sim 9.4 \%)$ received grants of $\$ 100,000$ each during the first nineteen rounds of the GCE program.

We use the identifying information on reviewers and applicants to obtain information on institutional affiliation, gender, country of residence, and area of expertise. Notably, even at the proposal stage, we find a significant gender gap: our sample of US-based academic applicants is $66 \%$ male. In addition to obtaining demographic information, we obtain applicants' full publication histories in order to estimate research productivity both before and after the peer review process. Table 1 lists summary statistics for these and other key variables, while Figure 1 presents the distribution of proposals and ratings across topic areas. Using this data, we proceed to investigate the role of gender in the peer review process, and the ability of peer review to both evaluate and select promising research projects and innovations.

\section{TABLE 1 \& FIGURE 1 HERE}

\section{Analysis and Results}

\section{A. Determinants of Reviewer Evaluations: Evidence of Disparity}

Our results begin with Table 2, which examines the impact of gender on the scores received by applicants' proposals. Columns 1 through 4 evaluate the overall impact of applicant gender across all reviewers in our sample, while column 5 decomposes the effect between male and female reviewers by adding an interaction between applicant and reviewer genders. All specifications include fixed effects by GCE round; specification 2 adds reviewer characteristics, and specifications 3 through 5 include reviewer fixed effects. In addition, specifications 4 and 5 include

\footnotetext{
${ }^{6}$ It is worth noting that this rating system does not offer the opportunity for reviewers to send negative signals: proposals not receiving support from a given reviewer all receive the same rating (effectively, a score of zero), regardless of the reviewer's degree of disapproval.
} 
topic area fixed effects. In all specifications, we find consistent negative disparities for female applicants: such applicants are significantly less likely to receive high scores from reviewers. The effect size we estimate reflects our ordered-logit specification, reflecting a log-odds ratio that is approximately $16 \%$ lower than male applicants. In separate calculations, we find that this overall effect is driven by female applicants being approximately $15 \%$ less likely to receive a "silver" rating and $20 \%$ less likely to receive a "gold" rating from reviewers. In specification 5, we also include the interaction of female applicants and female reviewers; we find a strong positive effect for this variable. Importantly, this should not be interpreted to conclude that female reviewers have an affirmative preference for proposals from female applicants: the sum of the direct effect and the interaction is positive, but not significantly different from zero. ${ }^{7}$ Effectively, the direct effect captures the lower scores that female applicants receive from male reviewers, while the interaction term indicates that female reviewers do not exhibit a similar disparity in reviewer evaluations across gender.

Since the impact of applicant gender in Table 2 is robust to including topic-area fixed effects, our results suggest that the gender disparities we observe are not driven by applicants choosing lessvalued areas of study. We explore this question further in Figure 2, which compares the prevalence of female applicants against average proposal scores across the topic areas in our sample. We find that there is significant variation across topics in both dimensions; further, we find a weak positive relationship between the rate of female applicants and the average of reviewer scores across topic. The patterns in Figure 2 therefore lend additional support that the choice of topic is not a significant driver of the gender disparities in our sample.

\section{TABLE 2 \& FIGURE 2 HERE}

\footnotetext{
${ }^{7}$ Only 20 of $132(\sim 15 \%)$ reviewers in our sample are female, and in combination with the low proportion of female applicants, we lack the statistical power to precisely estimate the interaction between female reviewers and applicants.
} 
In Table 3, we continue our analysis of demographic disparities in reviewer scores, adding explicit controls for applicant quality using the measure of pre-period publications. ${ }^{8}$ Panel A explores a range of publication-based metrics, and finds that the female applicants in our sample are at a disadvantage relative to male applicants across all measures. We begin with career length in specifications 1 and 2, where we find that female applicants are approximately $30 \%$ less senior than male applicants, as measured by the number of years from an applicant's first academic publication. This result is robust to adding topic fixed effects in specification 2 . We perform similar analyses for the number of publications, and the share of top-journal and last-author publications, all in the three years prior to applying to the GCE program. Across all three measures, we find that female applicants are at a significant disadvantage, though this effect diminishes significantly after controlling for topic-area fixed effects and applicant career length. Overall, these results suggest the possibility that within our sample, female applicants have weaker publication histories, and may therefore have less ability to generate a high-scoring proposals.

We evaluate the impact of this difference in prior publications in Panel B, where we repeat the analysis of Table 2 while controlling for the details of applicants' publication history. We find a significant positive impact of prior publications on reviewer scores in specification 2; after including additional measures, we find that the share of top-journal publications is the strongest predictor of reviewer scores in our setting. Overall, we find strong evidence for the hypothesis that applicants with a superior publication history tend to generate higher-scoring proposals. However, even after controlling for a range of measures of applicants' prior publications, we continue to find a significant disadvantage for female applicants in all specifications. This pattern of results

\footnotetext{
${ }^{8}$ Specifically, we define the "pre-period" as the three years prior to the proposal's application year.
} 
suggests that the ex-ante differences in publication patterns across gender do not explain a significant portion of the outcome disparities we find in the proposal-evaluation process.

\section{TABLES 3A \& 3B HERE}

\section{B. Mechanisms Driving Disparity: Repeat Applications}

Having presented evidence for consistent gender disparities in reviewer scores, we now proceed to evaluate the mechanisms through which they might emerge even under a blinded-review process. The first potential mechanism is that of persistence: might female applicants be more easily discouraged if their first proposal is rejected? We evaluate this dimension in Panel A of Table 4, where we find that female applicants are significantly less likely to reapply after an initial rejection. This negative association becomes insignificant in specifications 3 and 4 after controlling for career length, suggesting that experience can lead to increased persistence that mitigates this aspect of gender disparity. We then proceed to evaluate the impact of this difference in Panel B; we show that repeat applicants receive significantly higher scores than first attempts. This effect is both strong and highly robust, persisting in all specifications as we include topic fixed effects, publication characteristics, and interaction effects. Our results therefore serve as a reminder of the value of persistence in the face of rejection; in light of the results in Panel A, this is advice that is particularly important for female researchers and innovators at the early stages of their career. ${ }^{9}$ However, controlling for this repeat-applicant effect does not meaningfully reduce the gender disparity we identified in Tables 2 and 3. Thus, while repeat applicants are expected to receive significantly higher scores from reviewers, this dimension does not explain a significant portion the female score disparity in our sample.

\section{TABLES 4A \& 4B HERE}

\footnotetext{
${ }^{9}$ While repeat applicants receive a significant boost in terms of their expected scores from reviewers, the interaction between female applicants and repeat applicants in specifications 5 and 6 are insignificant. Thus, there is no additional boost to female applicants who re-apply after rejection, relative to male applicants who do the same.
} 


\section{C. $\quad$ Mechanisms Driving Disparity: Word Choice}

A second potential mechanism to explain demographic disparities in an anonymous review process is the set of words that applicants use to describe their proposals. Specifically, we analyze the words present in the title and descriptions of applicants' proposals, after removing standard conjunctions, pronouns, and linking words. In Figures 3 and 4, we plot words based on their relative rates of use by male and female applicants, and include 45 -degree lines to clearly separate "male" from "female" words in our data. We present the 100 most frequent of the remaining words in Figure 3, in order to show that word use rates are strongly correlated across applicant gender. While the overall correlation is strong, there is nevertheless significant variation in the gender use rates of some words. Figure 4 highlights this trend by focusing on words that have a significant correlation with reviewer scores, and also identifies the difference between "narrow" words (those which appear significantly more often in some topics than others), and "broad" words (which appear at similar rates in all topic areas). The latter figure suggests that male applicants tend to favor broad words, while female applicants have a tendency to use narrow words. Overall, these figures identify the similarities and difference in word choice across applicant gender, and set the stage for analyzing whether the differences we find can explain the gender score gap in our sample.

\section{FIGURES 3 \& 4 HERE}

In addition to disparities in use rates across applicant gender, the frequent words in our sample also have significant disparities in their tendencies to appear within high- and low-scoring proposals. We highlight these score disparities in Figure 5, plotting frequent (i.e. top-100) words that are disproportionately associated with male or female applicants based on their rates of use within high- and low-scoring proposals. While there is a reasonable amount of variation across words, the overall pattern suggests that words falling well below the 45-degree line (i.e. those with strongly negative score disparities) are much more likely to be used disproportionately by female 
applicants. By contrast, most "male" words are likely to be near or above the 45-degree line, indicating a positive score disparity. We follow up the binary analysis of gender in Figure 5 with a full two-dimensional exploration of gender- and score-based disparities in Figure 6. This figure highlights the positive relationship between words used more often by male applicants, and words associated with high-scoring proposals. Importantly, while most "male" words have a positive score disparity, there are "female" words with both positive and negative score disparities. This effect seems to be associated with the difference between broad and narrow words: the broad words in Figure 6 seem to be driving the high scores of male applicants, while the narrow words seem to be associated with the lower scores of female applicants. This suggests that there is significant scope for female applicants to improve their scores by altering the words they use to describe their proposals.

\section{FIGURES 5 \& 6 HERE}

In light of the patterns described above, we now proceed to explore the impact of word choice on reviewer scores using a regression framework in Table 5. We begin with Panel A, which highlights some of the basic patterns of word choice in our sample, focusing on the top 1,000 most frequent words used in the proposals in our sample. We examine the differences in word use between male and female applicants, and in specification 1, we show that the total number of frequent words does not differ across gender. By contrast, we find significant differences across applicant gender in all remaining word-choice measures: female applicants use fewer high-scoring words and more low-scoring words in specifications 2 and 3, and this result is robust to identifying high- and lowscoring words using only male applicants' proposals in specifications 4 and 5 . Finally, in specifications 6 and 7, we classify words as "broad" and "narrow" based on whether they are used at similar or different rates across topic areas, and show that female applicants use fewer broad words and more narrow words when describing their proposals. 
Having established these basic patterns, we next construct text-based measures of each proposal's quality as perceived by reviewers. Specifically, we predict a proposal's reviewer scores based only on the presence or absence of the top 500 most score-influencing words in each proposal's title and description. Importantly, to avoid circular reasoning, we calibrate our text-based reviewer score predictions using only the proposals from male applicants. Thus, the high-and low-scoring words we identify are those with which male applicants receive high and low scores from reviewers, with no information regarding the use of these words by female applicants. We normalize score predictions to a mean of zero and unit standard deviation, and proceed to use them as dependent variables in Panel B, and explanatory variables in Panel C.

In Panel B, we analyze the relationship between applicant gender and our text-based measures of proposal quality. Specifications 1 through 3 demonstrate this result using the full set of 500 words, while specifications 4 and 5 explore the division between high-scoring and low-scoring words, respectively Finally, in specifications 6 and 7, we focus solely on broad and narrow words, respectively. In all cases, we find strong evidence that female applicants use words that diminish their chances of receiving high scores from reviewers. In addition, we find that female applicants are at a greater disadvantage in their use of narrow words, compared to their disadvantage in the use of broad words.

Having established the baseline result that female applicants' word choices put them at a disadvantage, we now turn to the impact of those word choices on reviewer scores in Panel C. Our analysis begins in specification 2, where we control for a wide range of text-based metrics such as the count of unique frequent words, grammatical composition, and the grade level ${ }^{10}$ of proposal text. While a number of these measures have a significant association with reviewer scores, they

\footnotetext{
${ }^{10}$ Our measure of grade level is a composite rating based on the arithmetic average of the Flesch-Kincaid, GunningFog, and SMOG measures. See Hengel (2017) for details.
} 
do not significantly reduce the observed gender gap in our sample. However, when we add the text-based score predictions starting in specification 3, we see a large drop in the coefficient on female applicants. The inclusion of the score prediction based on narrow words again seems to be a major driver of the gender gap, as it renders the applicant gender effect insignificant, while the score prediction based on broad words fails to do so. When controlling for both measures, we continue to find no significant effect of applicant gender on reviewer scores, even as we add controls for topic areas and applicant publications. Notably, these measures do not eliminate the interaction between female applicants and female reviewers, which remains positive and significant. ${ }^{11}$ Table 5 therefore highlights word choice as a crucial driver of gender disparities, even under blinded review.

\section{TABLES 5A, 5B, \& 5C HERE}

Having covered a range of mechanisms individually, we now synthesize our prior analyses of reviewer scores to examine the relative impact of each dimension in contributing to gender -based disparities. Table 6 presents our results, beginning with the baseline analysis in column 1, which controls only for the round of the program, reviewer fixed effects, and reviewer-cross-round characteristics. Adding gender-based interactions between applicants and reviewers in column 2 increases the magnitude of the applicant gender effect, which now reflects the scoring patterns of male reviewers. Moving to column 3, we add topic-area fixed effects, which reduce the magnitude of the gender gap by approximately ten percent. In column 4, we add publication characteristics, which lead to only a marginal $3 \%$ further decline in the gender gap. In column 5 , we add the mechanism of repeat applications, which also explains only $3 \%$ of the gender score-gap. In column 6, we introduce a range of text-based controls such as word count, grammatical composition, the

\footnotetext{
${ }^{11}$ Indeed, in this specification, the sum of the baseline effect and the interaction is positive and significant, indicating that female reviewers have an affirmative preference for female applicants, after controlling for text-based score predictions derived from male applicants' proposals.
} 
rate of scientific words, and the grade level of proposal text; these measures offer only a $2 \%$ decrease in the gender gap. Finally, in column 7, we control for word choice in the form of our text-based score prediction; this eliminates over $50 \%$ of the remaining gender score gap, and renders the overall disparity insignificant. Importantly, these controls do not reduce the interaction effect that we find between female applicants and reviewers, suggesting that female reviewers are not influenced by word choice in the same way as male reviewers. Thus, the main conclusion of Table 6 is that the gender score-gap is driven in large part by the choice of words female applicants use to describe their proposals; after controlling for this dimension, the disparity falls by more than $50 \%$ and is no longer statistically significant.

\section{TABLE 6 HERE}

\section{The Impact of Gender on Innovative Outcomes}

So far, our results have focused on explaining the disparities in reviewer scores received by female applicants. While this is inherently valuable as a means of identifying the underlying causes of the lack of demographic diversity in innovative fields, it does not address questions related to efficiency: does the lack of gender diversity in high-scoring applicants reflect an inefficient disparity and unreasonable barriers, or is it a reflection of the fact that female applicants face challenges that are likely to interfere with their performance, even if they were selected by reviewers? To address these questions, we analyze ex-post outcomes for our sample of applicants, looking specifically at publications, NIH grants, and Phase-2 outcomes within the GCE program. Our results begin in Table 7 , which focuses specifically on funded applicants: conditional on funding, how did different demographic groups perform? This "treatment-on-treated" analysis is meant to capture the organizational perspective: did the evaluation process select the strongest applicants, regardless of demographic characteristics? We consider a wide range of outcomes, and show that in most cases, the review process did indeed select a pool where there were no significant 
differences between demographic groups. In particular, in columns 1 through 7, after controlling for proposal scores and pre-period outcomes, we find no ex-post disparities in publication-related outcomes across applicant gender. By contrast, in columns 8 and 9, we find (weak) evidence of gender's impact on innovative outcomes. Focusing on the outcome of NIH grants in column 8 , we find that female applicants are slightly more likely to obtain such grants in the post-proposal period; we also find a large but insignificant point-estimate for the high-value R01 grants that cover multiple years of research in column 9. Importantly, all specifications also control for word choice, which has a different impact here relative to our earlier tables. Previously, we highlighted that male applicants seemed to benefit in terms of reviewer scores by using general words more often, while female applicants tended to use topic-specific words, which tended to lead to lower reviewer scores. By contrast, Table 7 suggests that while using broad words may help obtain high scores from reviewers, such proposals do not tend to perform as well in terms of ex-post outcomes. In effect, reviewers may well be overly credulous to the broad claims of such proposals, which tend to under-perform across multiple measures if selected for GCE funding.

\section{TABLE 7 HERE}

The focus on the sub-sample of funded applicants is valuable, but it is not always the correct perspective for evaluating the relationship between demography and innovation. While Table 7 captures the effectiveness of the selection process, it does not offer insight into the impact of funding on the applicants in our sample. It may well be the case that some of the applicants receiving funding would have done just as well without it, perhaps because of access to other sources of money or support. To evaluate the causal impact of funding, we therefore need to compare funded applicants against those who (just barely) did not receive funding. In Table 8 , we establish a difference-in-differences estimator by focusing on the sub-sample of proposals, which 
received positive reviews from at least one reviewer. Within this "high-scoring" sample, we examine not only the baseline impact of funding, but also its differential impact across genders. We begin our analysis in columns 1 and 2, focusing on all published articles and on articles published in top journals, ${ }^{12}$ respectively. We find that while funding has only a weakly-positive and insignificant impact on publications, there is a significant positive interaction between funding and female applicants, particularly for top-journal publications. This suggests that Gates foundation funding has a significantly greater impact when it is allocated to female applicants, relative to male applicants. The reason for this difference seems to be driven in part by the negative baseline effect for female applicants: without funding, they under-perform male applicants, and this effect is once again stronger for top-journal publications. A similar pattern appears in columns 3 through 5, which track novelty and exploration by tracking new journals, coauthors, and MeSH terms derived from applicants' publications. In all three outcome measures, we find that the baseline effect of being a female applicant is significantly negative, indicating that unfunded women are likely to perform worse than unfunded men. However, we also find positive interaction effects between funding and female applicants, leading to no significant difference across gender between funded applicants. Once again, our difference-in-differences results come not from funded women outperforming men, but from unfunded women significantly under-performing unfunded men. In effect, securing funding from the GCE program can "level the playing field" for female applicants, and generates a larger impact than the funding devoted to male applicants. In line with our earlier results on the importance of funding, we turn to the results focusing on NIH grants in columns 6 and 7. The overall pattern of results is similar in both cases, but the strongest effects can be seen in column 7, which focuses on the coveted multi-year R01 grants. For this

\footnotetext{
${ }^{12}$ We define top journals as those in the top decile of impact factor. Our results are robust to redefining top journals as either top- $5 \%$ or top- $25 \%$ by impact factor.
} 
outcome, we see negative but insignificant baseline effects for female applicants. More importantly, we find strong positive interactions between female applicants and GCE funding, with

the positive interaction effects more-than-compensating for the negative baseline impacts of demographics. We can therefore conclude that female applicants' careers are more responsive to funding in this outcome dimension: the GCE program's impact is most beneficial to these groups when it leads them to obtain additional funding from the NIH, especially through its R01 program. This implies that GCE funding can lead to a "multiplier effect," where it allows successful applicants to be more effective at raising external funding as their careers progress.

Finally, revisiting the impact of proposal text, we once again find that the use of broad and narrow words, do not predict an increase in any of our ex-post outcomes. By contrast, the metric of proposal text grade level, which did not predict reviewer scores in Tables $5 \mathrm{C}$ and 6 , is now a significant positive predictor of virtually all measures of follow-on innovation. This suggests that while communication style does offer valuable information on the quality of applicants' ideas, reviewers are focusing on the wrong metrics when evaluating the innovative proposals in our sample.

\section{TABLE 8 HERE}

\section{Discussion and Conclusions}

In this paper, we addressed two primary research questions: first, how can innovative organizations become more diverse along the dimension of gender, and second, what are the potential impacts on innovation from an increase in gender inclusion? By taking advantage of our unique empirical setting and its blinded-review process, we were able to eliminate the direct effects of bias and discrimination, and focus exclusively on the indirect mechanisms that contribute to the gender disparities in our sample. Our main contributions are the identification of word choice as an important driver of negative outcomes for female innovators, and the finding that women may 
offer a greater return on an organization's resources, in terms of future innovative outcomes. Our findings suggest a number of important outstanding questions for future research.

First, our analysis of innovative outcomes only offers a limited duration of ex-post data following GCE funding decisions, particularly for applicants in later rounds. In this timeframe, we saw evidence that female applicants were able to obtain significantly more additional NIH funding as a result of a successful application. While obtaining funding from the NIH or similar organizations is not an end-goal by itself, this additional funding can be reasonably expected to serve as an input to future research and innovation. While our sample period is too short to capture these dynamics, allocating more resources to female innovators may well lead to improved career trajectories and greater innovative output, especially over longer horizons. Indeed, if the findings in our sample apply to the broader scientific and innovative communities, it is likely that female innovators are systematically under-funded relative to the quality of their ideas. Future work could explore these patterns across longer time horizons and in other stages of the innovation ecosystem.

Second, our text-based analysis focuses on the relatively straightforward measure of the presence or absence of commonly-used words; a more sophisticated analysis of a larger sample would offer the opportunity to identify detailed patterns in the types of words that either help or harm evaluations, particularly for female innovators. Finally, we were unable to effectively explore dimensions of diversity other than gender in our sample, due to low number of applicants in other under-represented categories (e.g. racial minorities.) More work is needed to determine whether our results are generalizable to other dimensions of organizational diversity. Thus, we would encourage future research to look to other dimensions of diversity, such as ethnicity, national origin, and socio-economic status, as key drivers of the innovative process. 


\section{References}

Azoulay, P., Graff Zivin, J. S., \& Manso, G. (2011). Incentives and creativity: evidence from the academic life sciences. The RAND Journal of Economics, 42(3), 527-554.

Becker, G. S. (2010). The economics of discrimination. University of Chicago press.

Bell, A. M., Chetty, R., Jaravel, X., Petkova, N., \& Van Reenen, J. (2017). Who Becomes an Inventor in America? The Importance of Exposure to Innovation (No. w24062). National Bureau of Economic Research.

Bilimoria, D., Joy, S., \& Liang, X. (2008). Breaking barriers and creating inclusiveness: Lessons of organizational transformation to advance women faculty in academic science and engineering. Human Resource Management, 47(3), 423-441.

Boudreau, K. J., Guinan, E. C., Lakhani, K. R., \& Riedl, C. (2016). Looking across and looking beyond the knowledge frontier: Intellectual distance, novelty, and resource allocation in science. Management Science, 62(10), 2765-2783.

Brooks, A. W., Huang, L., Kearney, S. W., \& Murray, F. E. (2014). Investors prefer entrepreneurial ventures pitched by attractive men. Proceedings of the National Academy of Sciences, 111(12), 4427-4431.

Castilla, E. J. (2008). Gender, race, and meritocracy in organizational careers. American Journal of Sociology, 113(6), 1479-1526.

Castilla, E. J. (2015). Accounting for the gap: A firm study manipulating organizational accountability and transparency in pay decisions. Organization Science, 26(2), 311-333.

Castilla, E. J., \& Benard, S. (2010). The paradox of meritocracy in organizations. Administrative Science Quarterly, 55(4), 543-676.

Cook, L. D., \& Kongcharoen, C. (2010). The idea gap in pink and black (No. w16331). National Bureau of Economic Research.

Cook, C., Diamond, R., Hall, J., List, J. A., \& Oyer, P. (2018). The Gender Earnings Gap in the Gig Economy: Evidence from over a Million Rideshare Drivers. Working paper. Available at: https://web.stanford.edu/ diamondr/UberPayGap.pdf

Fernandez, R. M., \& Campero, S. (2014). Does Competition Drive Out Discrimination? In New Haven, CT: Presentation at Economy and Society@Yale Conference.

Fernandez, R. M., \& Campero, S. (2017). Gender sorting and the glass ceiling in high-tech firms. ILR Review, 70(1), 73-104.

Fernandez, R. M., \& Fernandez-Mateo, I. (2006). Networks, race, and hiring. American sociological review, 71(1), 42-71.

Ginther, D. K., Kahn, S., \& Schaffer, W. T. (2016). Gender, race/ethnicity, and National Institutes of Health R01 research awards: is there evidence of a double bind for women of color? Academic medicine: journal of the Association of American Medical Colleges, 91(8), 1098.

Goldin, C., \& Rouse, C. (2000). Orchestrating impartiality: The impact of" blind" auditions on female musicians. American economic review, 90(4), 715-741.

Gompers, P. A., \& Wang, S. Q. (2017). Diversity in innovation (No. w23082). National Bureau of Economic Research. 
Hengel, E. (2017). Publishing while Female. Are women held to higher standards? Evidence from peer review. Working paper.

Kaatz, A., Magua, M. W., Zimmerman, D. R., \& Carnes, M. (2015). A quantitative linguistic analysis of National Institutes of Health R01 application critiques from investigators at one institution. Academic medicine: journal of the Association of American Medical Colleges, 90(1), 69.

Kelly, E. L., Ammons, S. K., Chermack, K., \& Moen, P. (2010). Gendered challenge, gendered response: Confronting the ideal worker norm in a white-collar organization. Gender \& Society, 24(3), 281-303.

Kunze, A., \& Miller, A. R. (2017). Women helping women? Evidence from private sector data on workplace hierarchies. Review of Economics and Statistics, 99(5), 769-775.

Lerchenmueller, M. J., \& Sorenson, O. (2018). The gender gap in early career transitions in the life sciences. Research Policy, 47(6), 1007-1017.

Lincoln, A. E., Pincus, S., Koster, J. B., \& Leboy, P. S. (2012). The Matilda Effect in science: Awards and prizes in the US, 1990s and 2000s. Social studies of science, 42(2), 307-320.

Magua, W., Zhu, X., Bhattacharya, A., Filut, A., Potvien, A., Leatherberry, R., ... \& Kaatz, A. (2017). Are female applicants disadvantaged in National Institutes of Health peer review? Combining algorithmic text mining and qualitative methods to detect evaluative differences in R01 reviewers' critiques. Journal of Women's Health, 26(5), 560-570.

Marschke, G., Nunez, A., Weinberg, B. A., \& Yu, H. (2018). Last Place? The Intersection between Ethnicity, Gender, and Race in Biomedical Authorship.

McIntyre, S., Moberg, D. J., \& Posner, B. Z. (1980). Preferential treatment in preselection decisions according to sex and race. Academy of Management Journal, 23(4), 738-749.

McKown, C., \& Weinstein, R. S. (2002). Modeling the Role of Child Ethnicity and Gender in Children's Differential Response to Teacher Expectations 1. Journal of Applied Social Psychology, 32(1), 159-184.

Monroe, K., Ozyurt, S., Wrigley, T., \& Alexander, A. (2008). Gender equality in academia: Bad news from the trenches, and some possible solutions. Perspectives on politics, 6(2), 215-233.

Murray, F., \& Graham, L. (2007). Buying science and selling science: gender differences in the market for commercial science. Industrial and Corporate Change, 16(4), 657-689.

Østergaard, C. R., Timmermans, B., \& Kristinsson, K. (2011). Does a different view create something new? The effect of employee diversity on innovation. Research Policy, 40(3), 500509.

Poppenhaeger, K. (2017). Unconscious Gender Bias in Academia: from PhD Students to Professors. arXiv preprint arXiv:1711.00344.

Reagans, R., \& Zuckerman, E. W. (2001). Networks, diversity, and productivity: The social capital of corporate R\&D teams. Organization science, 12(4), 502-517.

Reuben, E., Sapienza, P., \& Zingales, L. (2014). How stereotypes impair women's careers in science. Proceedings of the National Academy of Sciences, 201314788.

Robinson, G., \& Dechant, K. (1997). Building a business case for diversity. Academy of Management Perspectives, 11(3), 21-31. 
Schmader, T., Whitehead, J., \& Wysocki, V. H. (2007). A linguistic comparison of letters of recommendation for male and female chemistry and biochemistry job applicants. Sex roles, 57(78), 509-514.

Shen, H. (2013). Mind the gender gap. Nature, 495(7439), 22.

Sood, G., \& Laohaprapanon, S. (2018). Predicting Race and Ethnicity from the Sequence of Characters in a Name. arXiv preprint arXiv:1805.02109.

Tasheva, S. N., \& Hillman, A. (2018). Integrating diversity at different levels: multi-level human capital, social capital, and demographic diversity and their implications for team effectiveness. Academy of Management Review, (ja).

Witteman, H. O., Hendricks, M., Straus, S., \& Tannenbaum, C. (2017). Female grant applicants are equally successful when peer reviewers assess the science, but not when they assess the scientist. bioRxiv, 232868.

Wold, A., \& Wenneras, C. (2010). Nepotism and sexism in peer-review. In Women, science, and technology (pp. 64-70). Routledge. 
Figure 1: Distribution of Proposals, Applicants, and Scores by Topic

Observations: 6794 Total Proposals, 1933 Silver Ratings, 409 Gold Ratings

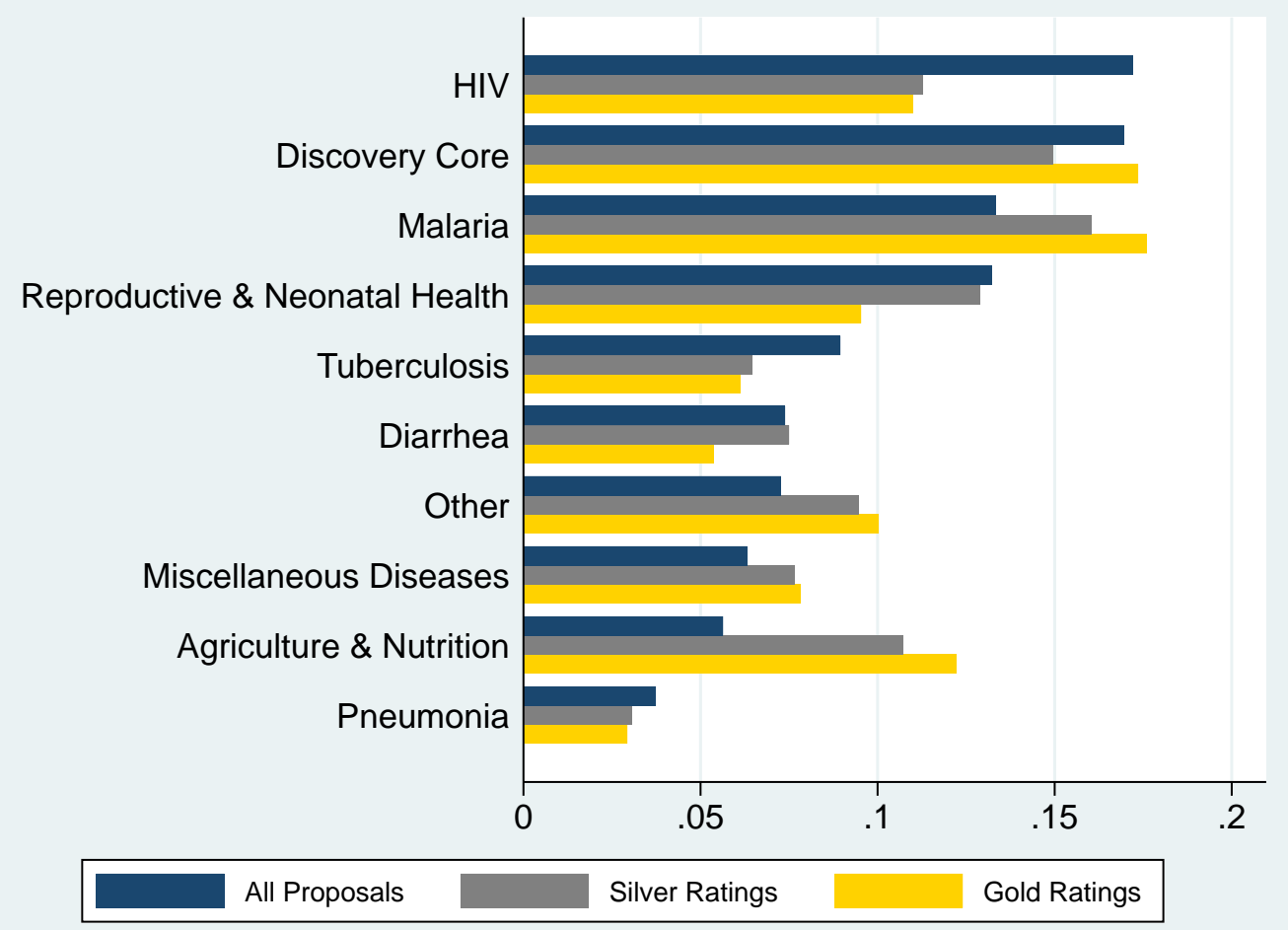

Figure 2: Rates of Female Applicants and Average Scores by Topic

Note: Circle areas represent the number of proposals in each topic. Total Proposals: 6794

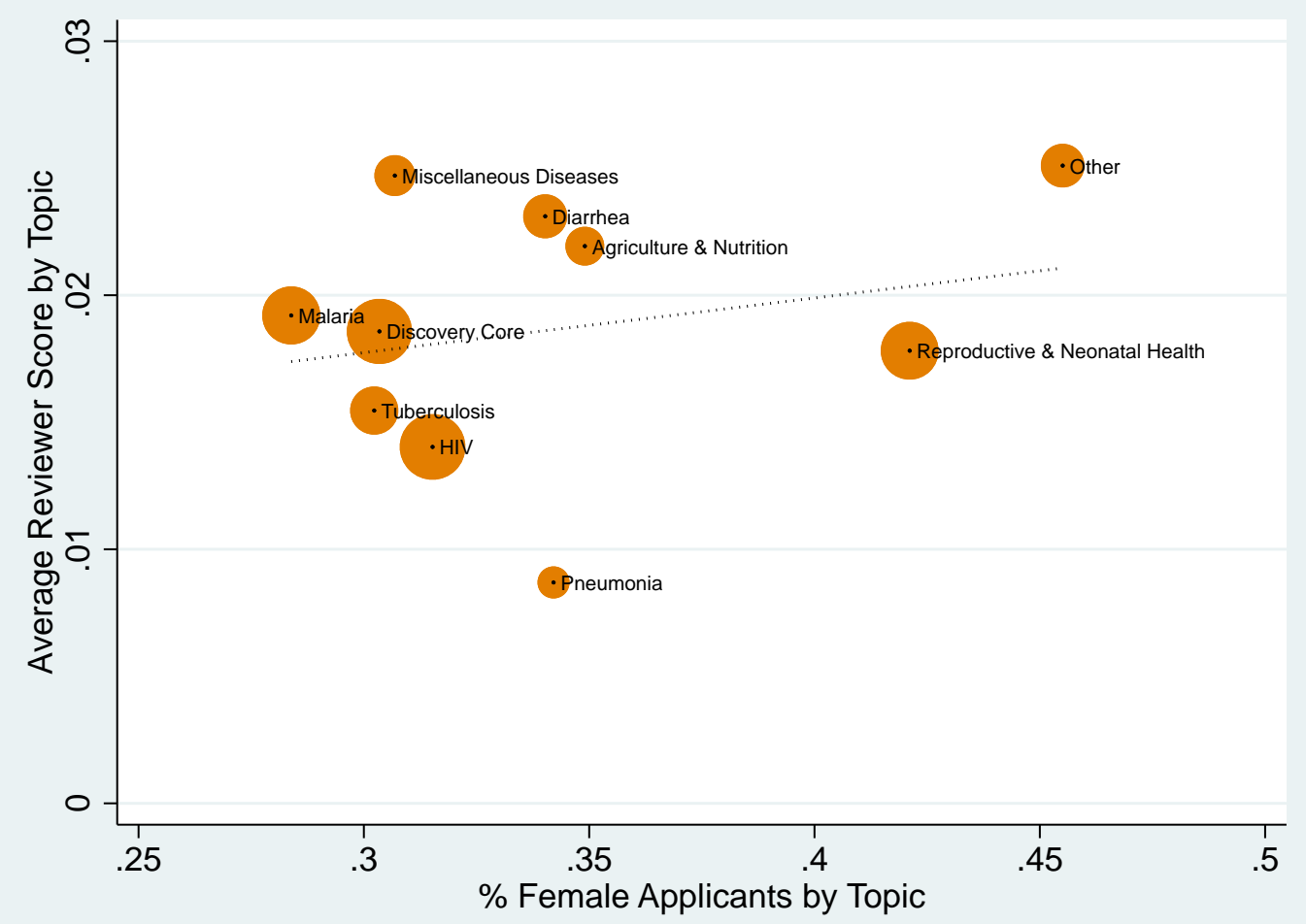


Figure 3: Male vs. Female Word Use Rates for All Frequent Words

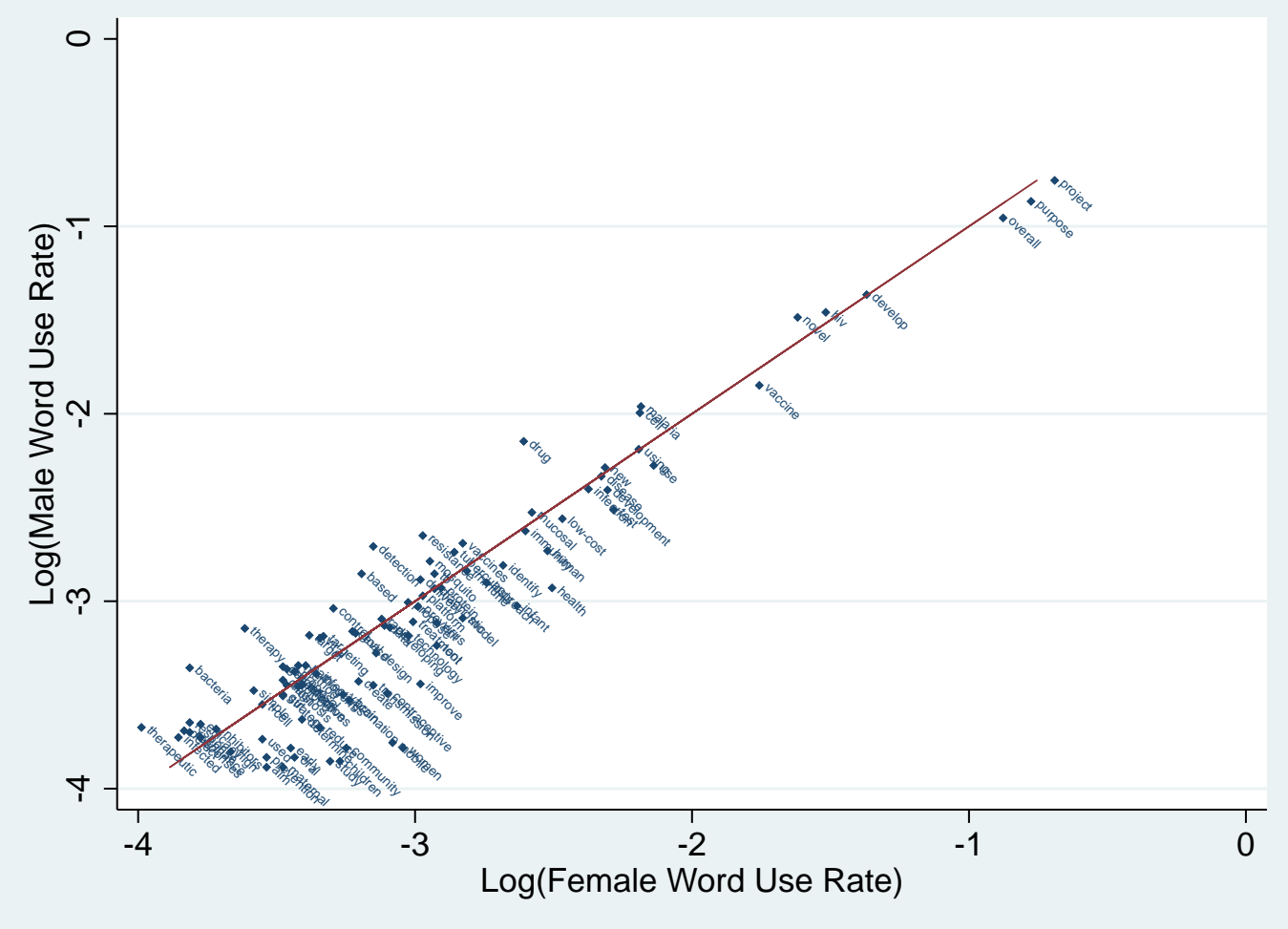

Figure 4: Male vs. Female Word Use Rates for Broad vs. Narrow Words

Note: Words selected based on high use frequency and significant correlation with proposal score. Narrow (broad) words are defined based on a high (low) variance in use rate across proposal topics.

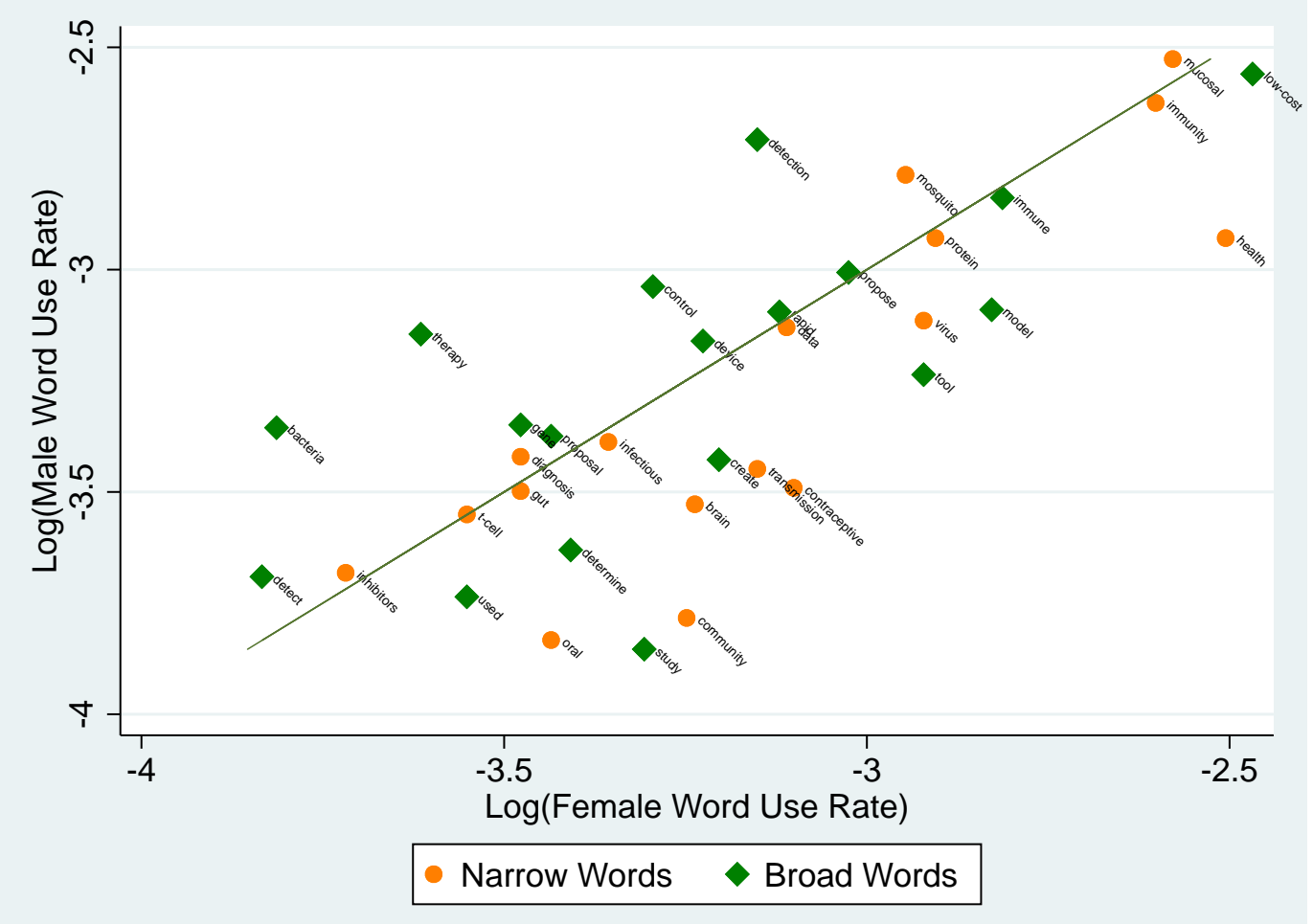


Figure 5: High-Scoring vs. Low-Scoring Word Use Rates for Gendered Frequent Words

Note: Words selected based on high use frequency and significant correlation with applicant gender.

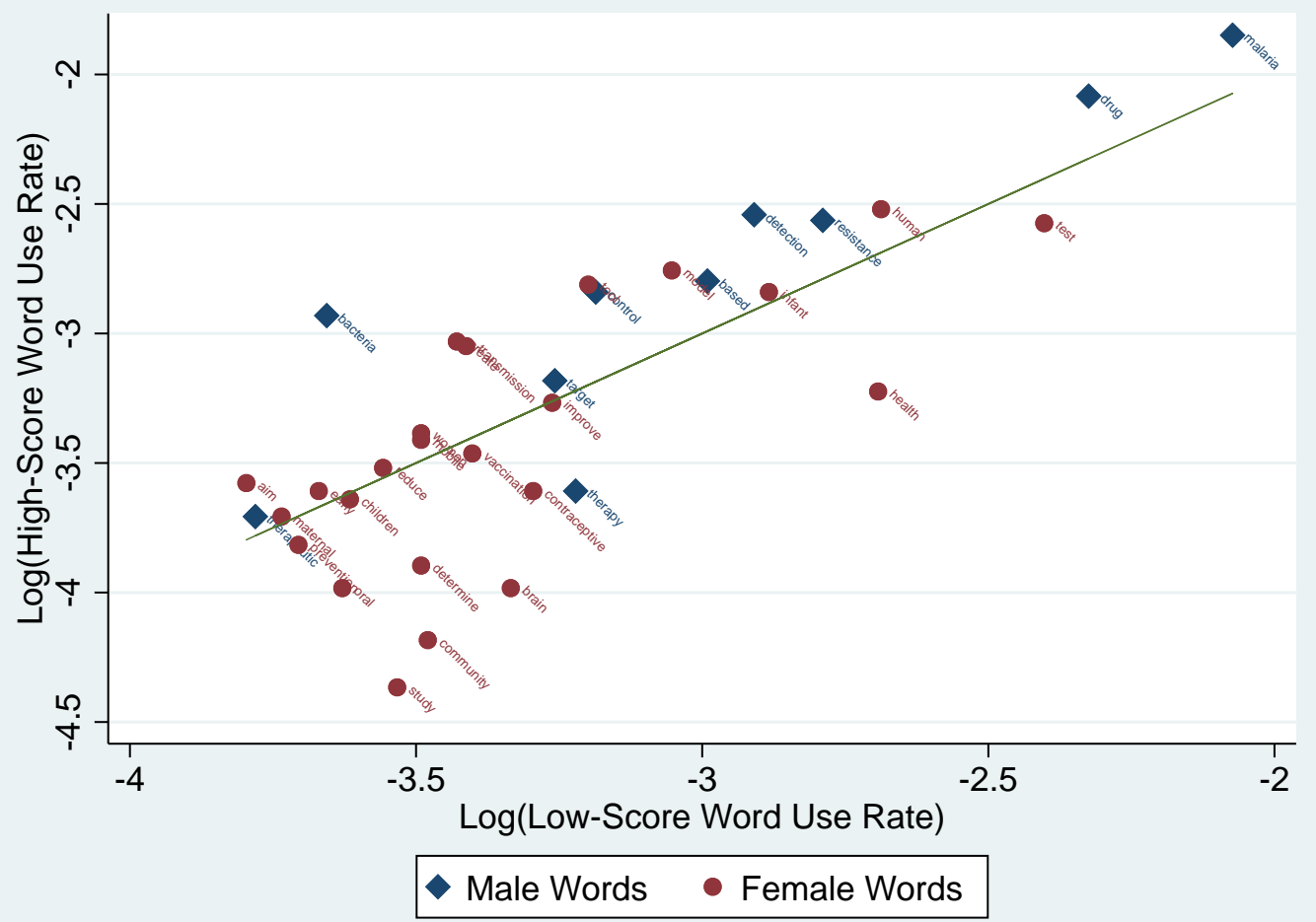

Figure 6: Frequent Words with Disparities in Reviewer Scores and Gender-Based Use

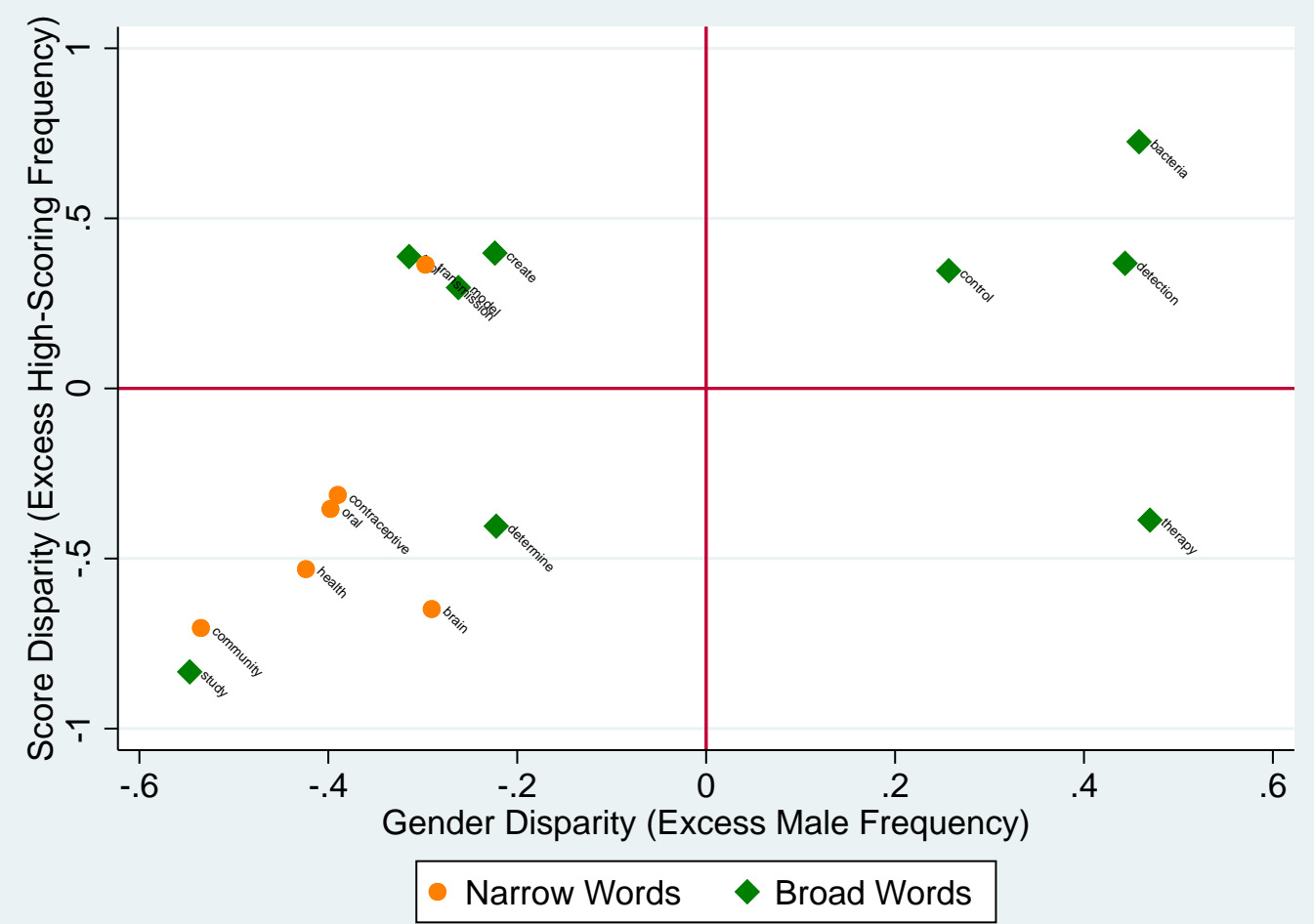




\begin{tabular}{|c|c|c|c|c|c|}
\hline Variable & N. of Obs. & Mean & Std. Dev. & Min & $\operatorname{Max}$ \\
\hline \multicolumn{6}{|l|}{ APPLICANT CHARACTERISTICS } \\
\hline Female Applicant Probability & 5,058 & 0.343 & 0.475 & 0 & 1 \\
\hline Applicant Publication History Indicator & 5,058 & 0.785 & 0.411 & 0 & 1 \\
\hline \multicolumn{6}{|l|}{ PROPOSAL CHARACTERISTICS } \\
\hline GCE Round & 6,794 & 6.083 & 5.198 & 1 & 19 \\
\hline Funding Indicator & 6,794 & 0.093 & 0.291 & 0 & 1 \\
\hline High-Score Indicator & 6,794 & 0.174 & 0.379 & 0 & 1 \\
\hline Reviewer Count & 6,794 & 3.158 & 1.324 & 1 & 7 \\
\hline Repeat-Applicant-After-Failure Indicator & 6,794 & 0.204 & 0.403 & 0 & 1 \\
\hline \multicolumn{6}{|l|}{ Proposal Text Characteristics: } \\
\hline Unique Frequent Word Count & 6,794 & 11.032 & 4.530 & 0 & 75 \\
\hline Noun Share & 6,794 & 0.370 & 0.096 & 0.00 & 1.00 \\
\hline Adjective Share & 6,794 & 0.163 & 0.079 & 0.00 & 0.75 \\
\hline Verb Share & 6,794 & 0.121 & 0.062 & 0 & 0.5 \\
\hline Proposal Text Grade Level & 6,794 & 15.954 & 3.035 & 1.78 & 30.65 \\
\hline Normalized Text-Based Score: Broad Words & 6,794 & 0.000 & 1.000 & -9.01 & 1.22 \\
\hline Normalized Text-Based Score: Narrow Words & 6,794 & 0.000 & 1.000 & -15.26 & 3.88 \\
\hline \multicolumn{6}{|l|}{ Conditional on Identifying Publication History: } \\
\hline Pre-Period Publications & 5,448 & 9.980 & 10.915 & 0 & 117 \\
\hline Post-Period Publications & 5,448 & 16.122 & 20.513 & 0 & 287 \\
\hline Pre-Period NIH Grants & 5,448 & 0.571 & 1.199 & 0 & 20 \\
\hline Post-Period NIH Grants & 5,448 & 0.857 & 1.672 & 0 & 17 \\
\hline \multicolumn{6}{|l|}{ REVIEWER CHARACTERISTICS } \\
\hline Female Reviewer Probability & 132 & 0.161 & 0.355 & 0 & 1 \\
\hline Avg. Proposals per Round (All-GCE) & 132 & 117.312 & 43.185 & 31 & 206 \\
\hline Avg. Proposals per Round (US Academics) & 132 & 47.950 & 24.964 & 5.5 & 99 \\
\hline \multicolumn{6}{|l|}{ REVIEWER X ROUND CHARACTERISTICS } \\
\hline Proposals Under Review & 429 & 116.9 & 50.5 & 31 & 210 \\
\hline Reviewer Round Sequence & 429 & 3.3 & 2.5 & 1 & 13 \\
\hline \multicolumn{6}{|l|}{ REVIEWER X PROPOSAL CHARACTERISTICS } \\
\hline Proposal Sequence & 21,453 & 71.6 & 48.9 & 1 & 208 \\
\hline Silver Rating & 21,453 & 0.049 & 0.215 & 0 & 1 \\
\hline Gold Rating & 21,453 & 0.011 & 0.103 & 0 & 1 \\
\hline
\end{tabular}


Table 2: Impact of Applicant and Reviewer Gender on Reviewer Scores

\begin{tabular}{|c|c|c|c|c|c|}
\hline & (1) & $(2)$ & (3) & (4) & (5) \\
\hline VARIABLES & & \multicolumn{4}{|c|}{ DV = Reviewer Score } \\
\hline Female Applicant & $\begin{array}{c}-0.165^{* * *} \\
(0.062)\end{array}$ & $\begin{array}{c}-0.163 * * * \\
(0.062)\end{array}$ & $\begin{array}{c}-0.163 * * * \\
(0.063)\end{array}$ & $\begin{array}{c}-0.141 * * \\
(0.064)\end{array}$ & $\begin{array}{c}-0.194 * * * \\
(0.071)\end{array}$ \\
\hline Female Reviewer & & $\begin{array}{c}0.052 \\
(0.053)\end{array}$ & & & \\
\hline Female Applicant X Female Reviewer & & & & & $\begin{array}{c}0.364 * * * \\
(0.138)\end{array}$ \\
\hline Reviewer X Round Characteristics: & & & & & \\
\hline Log(Proposals Under Review) & $\begin{array}{c}-0.812^{* * *} \\
(0.104)\end{array}$ & $\begin{array}{c}-0.840 * * * \\
(0.107)\end{array}$ & $\begin{array}{c}-0.658 * * * \\
(0.137)\end{array}$ & $\begin{array}{c}-0.759 * * * \\
(0.149)\end{array}$ & $\begin{array}{c}-0.764 * * * \\
(0.149)\end{array}$ \\
\hline Log(Reviewer Round Sequence) & $\begin{array}{c}0.008 \\
(0.038)\end{array}$ & $\begin{array}{l}-0.006 \\
(0.038)\end{array}$ & $\begin{array}{c}0.188 * * \\
(0.086)\end{array}$ & $\begin{array}{l}0.145^{*} \\
(0.086)\end{array}$ & $\begin{array}{l}0.141^{*} \\
(0.085)\end{array}$ \\
\hline Log(Proposal Sequence) & $\begin{array}{c}-0.088 * * \\
(0.036)\end{array}$ & $\begin{array}{c}-0.088^{* *} \\
(0.036)\end{array}$ & $\begin{array}{c}-0.091^{* *} \\
(0.036)\end{array}$ & $\begin{array}{c}-0.090 * * \\
(0.037)\end{array}$ & $\begin{array}{c}-0.090 * * \\
(0.037)\end{array}$ \\
\hline Round FEs & $\mathrm{Y}$ & $\mathrm{Y}$ & $\mathrm{Y}$ & $\mathrm{Y}$ & $\mathrm{Y}$ \\
\hline Reviewer FEs & $\mathrm{N}$ & $\mathrm{N}$ & $\mathrm{Y}$ & $\mathrm{Y}$ & $\mathrm{Y}$ \\
\hline Topic Area FEs & $\mathrm{N}$ & $\mathrm{N}$ & $\mathrm{N}$ & Y & Y \\
\hline Observations & 21,453 & 21,453 & 21,453 & 21,453 & 21,453 \\
\hline Pseudo R-squared & 0.0315 & 0.0317 & 0.0392 & 0.0432 & 0.0435 \\
\hline
\end{tabular}

Ordered logit specification; Robust standard errors clustered by reviewer in parentheses $* * * \mathrm{p}<0.01, * * \mathrm{p}<0.05, * \mathrm{p}<0.1$ 
Table 3A: Impact of Applicant Gender on Pre-Period Publications

\begin{tabular}{|c|c|c|c|c|c|c|c|c|}
\hline \multirow[b]{2}{*}{ Female Applicant } & $\begin{array}{l}\text { (1) } \\
\text { DV = Log } \\
\text { Career }\end{array}$ & $\begin{array}{l}\quad \text { (2) } \\
\text { Applicant } \\
\text { ength) }\end{array}$ & $\begin{array}{r}\text { (3) } \\
\text { DV = Log( } \\
\text { Public }\end{array}$ & $\begin{array}{l}\quad(4) \\
\text { re-Period } \\
\text { tions) }\end{array}$ & \multicolumn{2}{|c|}{$\begin{array}{c}\text { (5) } \\
\text { DV = Share of Top- } \\
\text { Journal Pre-Period } \\
\text { Publications }\end{array}$} & \multicolumn{2}{|c|}{$\begin{array}{c}(7) \\
\text { DV = Share of Last- } \\
\text { Author Pre-Period } \\
\text { Publications }\end{array}$} \\
\hline & $\begin{array}{c}-0.377^{* * *} \\
(0.034)\end{array}$ & $\begin{array}{c}-0.385 * * * \\
(0.034)\end{array}$ & $\begin{array}{c}-0.310 * * * \\
(0.035)\end{array}$ & $\begin{array}{c}-0.112 * * * \\
(0.031)\end{array}$ & $\begin{array}{c}-0.023 * * * \\
(0.008)\end{array}$ & $\begin{array}{l}-0.011 \\
(0.008)\end{array}$ & $\begin{array}{c}-0.071 * * * \\
(0.010)\end{array}$ & $\begin{array}{c}-0.022 * * \\
(0.009)\end{array}$ \\
\hline Log(Applicant Career Length) & & & & $\begin{array}{c}0.512 * * * \\
(0.014)\end{array}$ & & $\begin{array}{c}0.028 * * * \\
(0.004)\end{array}$ & & $\begin{array}{c}0.133^{* * *} \\
(0.003)\end{array}$ \\
\hline Round FEs & $\mathrm{Y}$ & $\mathrm{Y}$ & Y & $\mathrm{Y}$ & Y & Y & Y & Y \\
\hline Topic Area FEs & $\mathrm{N}$ & Y & $\mathrm{N}$ & $\mathrm{Y}$ & $\mathrm{N}$ & Y & $\mathrm{N}$ & Y \\
\hline Observations & 4,005 & 4,005 & 4,005 & 4,005 & 4,005 & 4,005 & 4,005 & 4,005 \\
\hline Pseudo R-squared & 0.043 & 0.054 & 0.025 & 0.249 & 0.012 & 0.030 & 0.037 & 0.220 \\
\hline
\end{tabular}

OLS specification; Robust standard errors in parentheses

$* * * p<0.01, * * p<0.05, * p<0.1$

Table 3B: Impact of Applicant Gender and Publication History on Reviewer Scores

\begin{tabular}{|c|c|c|c|c|c|}
\hline & (1) & (2) & (3) & (4) & (5) \\
\hline VARIABLES & & \multicolumn{4}{|c|}{ DV = Reviewer Score } \\
\hline Female Applicant & $\begin{array}{c}-0.163^{* * *} \\
(0.063)\end{array}$ & $\begin{array}{c}-0.164^{* *} \\
(0.065)\end{array}$ & $\begin{array}{c}-0.159 * * \\
(0.065)\end{array}$ & $\begin{array}{c}-0.134^{* *} \\
(0.066)\end{array}$ & $\begin{array}{c}-0.187^{* * *} \\
(0.070)\end{array}$ \\
\hline Female Applicant X Female Reviewer & & & & & $\begin{array}{c}0.359 * * * \\
(0.139)\end{array}$ \\
\hline Publication History Not Available & & $\begin{array}{l}-0.040 \\
(0.131)\end{array}$ & $\begin{array}{l}-0.015 \\
(0.129)\end{array}$ & $\begin{array}{c}0.018 \\
(0.129)\end{array}$ & $\begin{array}{c}0.017 \\
(0.129)\end{array}$ \\
\hline Log(Applicant Career Length) & & $\begin{array}{l}-0.067^{*} \\
(0.040)\end{array}$ & $\begin{array}{l}-0.079 * \\
(0.042)\end{array}$ & $\begin{array}{l}-0.067 \\
(0.042)\end{array}$ & $\begin{array}{l}-0.067 \\
(0.042)\end{array}$ \\
\hline Log(Pre-Period Publications) & & $\begin{array}{c}0.088^{* *} \\
(0.043)\end{array}$ & $\begin{array}{c}0.067 \\
(0.046)\end{array}$ & $\begin{array}{c}0.063 \\
(0.046)\end{array}$ & $\begin{array}{c}0.063 \\
(0.046)\end{array}$ \\
\hline Share of Top-Journal Pubs & & & $\begin{array}{c}0.349 * * \\
(0.138)\end{array}$ & $\begin{array}{c}0.346 * * \\
(0.139)\end{array}$ & $\begin{array}{c}0.344^{* *} \\
(0.139)\end{array}$ \\
\hline Share of Last-Author Pubs & & & $\begin{array}{c}0.102 \\
(0.111)\end{array}$ & $\begin{array}{c}0.092 \\
(0.115)\end{array}$ & $\begin{array}{c}0.091 \\
(0.115)\end{array}$ \\
\hline Round FEs & Y & Y & Y & Y & Y \\
\hline Reviewer FEs & Y & Y & Y & Y & Y \\
\hline Topic Area FEs & $\mathrm{N}$ & $\mathrm{N}$ & $\mathrm{N}$ & Y & Y \\
\hline Reviewer X Round Controls & Y & Y & $\mathrm{Y}$ & Y & Y \\
\hline Observations & 21,453 & 21,453 & 21,453 & 21,453 & 21,453 \\
\hline Pseudo R-squared & 0.0391 & 0.0396 & 0.0402 & 0.0441 & 0.0444 \\
\hline
\end{tabular}


Table 4A: Applicant Propensity to Re-Apply After Rejection

\begin{tabular}{lcccc}
\hline & \multicolumn{1}{c}{$(1)$} & $(2)$ & $(3)$ & $(4)$ \\
VARIABLES & \multicolumn{1}{c}{ DV $=$ Repeat Applicant After Rejection } \\
\hline & $-0.186^{* *}$ & $-0.177^{* *}$ & -0.098 & -0.100 \\
Female Applicant & $(0.084)$ & $(0.084)$ & $(0.086)$ & $(0.086)$ \\
Log(Applicant Career Length) & & & $0.256^{* * *}$ & $0.262^{* * *}$ \\
& & & $(0.049)$ & $(0.057)$ \\
Log(Pre-Period Publications) & & & & 0.059 \\
& & & & $(0.047)$ \\
Share of Top-Journal Pubs & & & & $-0.389^{* *}$ \\
& & & & $(0.195)$ \\
Round FEs & $\mathrm{N}$ & $\mathrm{Y}$ & $\mathrm{Y}$ & $\mathrm{Y}$ \\
Topic Area FEs & $\mathrm{N}$ & $\mathrm{N}$ & $\mathrm{N}$ & $\mathrm{Y}$ \\
Additional Publication Characteristics & & & & \\
& 4,496 & 4,462 & 4,462 & 4,462 \\
Observations & 0.0813 & 0.0860 & 0.0940 & 0.0952 \\
\hline Pseudo R-squared & & & &
\end{tabular}

Logit specification; Robust standard errors in parentheses

*** $p<0.01, * * p<0.05, * p<0.1$

Table 4B: Impact of Repeat Applicants on Reviewer Scores

\begin{tabular}{|c|c|c|c|c|c|c|}
\hline \multirow[b]{2}{*}{ VARIABLES } & (1) & (2) & (3) & (4) & (5) & (6) \\
\hline & \multicolumn{6}{|c|}{ DV = Reviewer Score } \\
\hline Female Applicant & $\begin{array}{c}-0.163^{* * *} \\
(0.063)\end{array}$ & $\begin{array}{c}-0.151^{* *} \\
(0.063)\end{array}$ & $\begin{array}{c}-0.130 * * \\
(0.064)\end{array}$ & $\begin{array}{c}-0.127^{*} \\
(0.065)\end{array}$ & $\begin{array}{c}-0.121^{*} \\
(0.070)\end{array}$ & $\begin{array}{c}-0.174 * * \\
(0.078)\end{array}$ \\
\hline Female Applicant X Repeat Applicant & & & & & $\begin{array}{l}-0.022 \\
(0.182)\end{array}$ & $\begin{array}{l}-0.020 \\
(0.182)\end{array}$ \\
\hline Female Applicant X Female Reviewer & & & & & & $\begin{array}{c}0.358^{* *} \\
(0.139)\end{array}$ \\
\hline Repeat Applicant After Rejection & & $\begin{array}{c}0.256 * * * \\
(0.061)\end{array}$ & $\begin{array}{c}0.252^{* * *} \\
(0.064)\end{array}$ & $\begin{array}{c}0.256 * * * \\
(0.064)\end{array}$ & $\begin{array}{c}0.262^{* * *} \\
(0.080)\end{array}$ & $\begin{array}{c}0.262^{* * *} \\
(0.080)\end{array}$ \\
\hline Log(Applicant Career Length) & & & & $\begin{array}{c}-0.079 * \\
(0.042)\end{array}$ & $\begin{array}{c}-0.079 * \\
(0.042)\end{array}$ & $\begin{array}{c}-0.078 * \\
(0.042)\end{array}$ \\
\hline Log(Pre-Period Publications) & & & & $\begin{array}{c}0.062 \\
(0.046)\end{array}$ & $\begin{array}{c}0.062 \\
(0.046)\end{array}$ & $\begin{array}{c}0.062 \\
(0.046)\end{array}$ \\
\hline Share of Top-Journal Pubs & & & & $\begin{array}{c}0.349 * * \\
(0.139)\end{array}$ & $\begin{array}{c}0.349 * * \\
(0.139)\end{array}$ & $\begin{array}{c}0.347 * * \\
(0.139)\end{array}$ \\
\hline Share of Last-Author Pubs & & & & $\begin{array}{c}0.092 \\
(0.115)\end{array}$ & $\begin{array}{c}0.092 \\
(0.114)\end{array}$ & $\begin{array}{c}0.091 \\
(0.114)\end{array}$ \\
\hline Round FEs & $\mathrm{Y}$ & $\mathrm{Y}$ & Y & Y & Y & Y \\
\hline Reviewer FEs & Y & Y & Y & Y & Y & Y \\
\hline Topic Area FEs & $\mathrm{N}$ & $\mathrm{N}$ & Y & $\mathrm{Y}$ & $\mathrm{Y}$ & Y \\
\hline Additional Publication Characteristics & $\mathrm{N}$ & $\mathrm{N}$ & $\mathrm{N}$ & Y & Y & Y \\
\hline Reviewer X Round Controls & $\mathrm{Y}$ & Y & Y & Y & Y & Y \\
\hline Observations & 21,453 & 21,453 & 21,453 & 21,453 & 21,453 & 21,453 \\
\hline Pseudo R-squared & 0.0392 & 0.0406 & 0.0445 & 0.0455 & 0.0455 & 0.0458 \\
\hline
\end{tabular}

Ordered logit specification; Robust standard errors clustered by reviewer in parentheses

*** $\mathrm{p}<0.01, * * \mathrm{p}<0.05, * \mathrm{p}<0.1$ 
Table 5A: Applicant Characteristics and Proposal Word Choice

\begin{tabular}{|c|c|c|c|c|c|c|c|}
\hline \multirow[b]{3}{*}{ VARIABLES } & (1) & (2) & (3) & (4) & (5) & (6) & (7) \\
\hline & \multicolumn{7}{|c|}{$\mathrm{DV}=$ Proposal Text Unique Word Count } \\
\hline & $\begin{array}{c}\text { All Frequent } \\
\text { Words }\end{array}$ & $\begin{array}{c}\text { High-Scoring } \\
\text { Words }\end{array}$ & $\begin{array}{l}\text { Low-Scoring } \\
\text { Words }\end{array}$ & $\begin{array}{c}\text { Male High- } \\
\text { Scoring Words }\end{array}$ & $\begin{array}{c}\text { Male Low- } \\
\text { Scoring Words }\end{array}$ & Broad Words & Narrow Words \\
\hline Female Applicant & $\begin{array}{c}0.007 \\
(0.007)\end{array}$ & $\begin{array}{c}-0.026 * * * \\
(0.007)\end{array}$ & $\begin{array}{c}0.055^{* * *} \\
(0.014)\end{array}$ & $\begin{array}{c}-0.019 * * * \\
(0.007)\end{array}$ & $\begin{array}{c}0.040 * * * \\
(0.014)\end{array}$ & $\begin{array}{c}-0.014^{* *} \\
(0.007)\end{array}$ & $\begin{array}{l}0.024 * * \\
(0.011)\end{array}$ \\
\hline Log(Frequent Word Count) & & $\begin{array}{c}1.123 * * * \\
(0.014)\end{array}$ & $\begin{array}{c}1.075 * * * \\
(0.025)\end{array}$ & $\begin{array}{c}1.119 * * * \\
(0.013)\end{array}$ & $\begin{array}{c}1.084 * * * \\
(0.025)\end{array}$ & $\begin{array}{c}1.139 * * * \\
(0.013)\end{array}$ & $\begin{array}{c}1.060^{* * *} \\
(0.024)\end{array}$ \\
\hline Noun Share & $\begin{array}{c}-0.027 \\
(0.045)\end{array}$ & $\begin{array}{c}-0.317 * * * \\
(0.039)\end{array}$ & $\begin{array}{c}0.584^{* * *} \\
(0.076)\end{array}$ & $\begin{array}{c}-0.362^{* * *} \\
(0.038)\end{array}$ & $\begin{array}{c}0.684 * * * \\
(0.079)\end{array}$ & $\begin{array}{c}-0.330 * * * \\
(0.038)\end{array}$ & $\begin{array}{c}0.481 * * * \\
(0.062)\end{array}$ \\
\hline Adjective Share & $\begin{array}{c}0.573^{* * *} \\
(0.051)\end{array}$ & $\begin{array}{c}0.484^{* * *} \\
(0.046)\end{array}$ & $\begin{array}{c}-0.950 * * * \\
(0.095)\end{array}$ & $\begin{array}{c}0.402 * * * \\
(0.045)\end{array}$ & $\begin{array}{c}-0.799 * * * \\
(0.097)\end{array}$ & $\begin{array}{c}0.303^{* * *} \\
(0.046)\end{array}$ & $\begin{array}{c}-0.443^{* * *} \\
(0.075)\end{array}$ \\
\hline Verb Share & $\begin{array}{c}0.554^{* * * *} \\
(0.063)\end{array}$ & $\begin{array}{c}0.328^{* * *} \\
(0.057)\end{array}$ & $\begin{array}{c}-0.592^{* * *} \\
(0.115)\end{array}$ & $\begin{array}{c}0.264^{* * *} \\
(0.056)\end{array}$ & $\begin{array}{c}-0.448^{* * * *} \\
(0.116)\end{array}$ & $\begin{array}{c}0.418^{* * *} \\
(0.057)\end{array}$ & $\begin{array}{c}-0.602 * * * \\
(0.093)\end{array}$ \\
\hline Proposal Text Grade Level & $\begin{array}{c}0.036 * * * \\
(0.002)\end{array}$ & $\begin{array}{c}-0.005 * * * \\
(0.001)\end{array}$ & $\begin{array}{c}0.014 * * * \\
(0.003)\end{array}$ & $\begin{array}{l}-0.001 \\
(0.001)\end{array}$ & $\begin{array}{c}0.006 * * \\
(0.003)\end{array}$ & $\begin{array}{l}-0.003^{*} \\
(0.001)\end{array}$ & $\begin{array}{c}0.006 * * * \\
(0.002)\end{array}$ \\
\hline Log(Applicant Career Length) & $\begin{array}{c}-0.009^{*} \\
(0.004)\end{array}$ & $\begin{array}{c}-0.003 \\
(0.004)\end{array}$ & $\begin{array}{c}0.007 \\
(0.009)\end{array}$ & $\begin{array}{c}-0.005 \\
(0.004)\end{array}$ & $\begin{array}{c}0.009 \\
(0.009)\end{array}$ & $\begin{array}{c}0.003 \\
(0.004)\end{array}$ & $\begin{array}{l}-0.005 \\
(0.007)\end{array}$ \\
\hline Share of Top-Journal Pubs & $\begin{array}{c}0.005 \\
(0.016)\end{array}$ & $\begin{array}{c}0.051 * * * \\
(0.015)\end{array}$ & $\begin{array}{c}-0.116 * * * \\
(0.035)\end{array}$ & $\begin{array}{c}0.046 * * * \\
(0.015)\end{array}$ & $\begin{array}{c}-0.103 * * * \\
(0.033)\end{array}$ & $\begin{array}{c}0.011 \\
(0.015)\end{array}$ & $\begin{array}{l}-0.019 \\
(0.026)\end{array}$ \\
\hline Round FEs & $\mathrm{Y}$ & $\mathrm{Y}$ & Y & Y & $\mathrm{Y}$ & $\mathrm{Y}$ & Y \\
\hline Topic Area FEs & $\mathrm{Y}$ & $\mathrm{Y}$ & Y & Y & Y & Y & Y \\
\hline Additional Text-Based Controls & $\mathrm{Y}$ & Y & Y & Y & Y & Y & Y \\
\hline Applicant Publication Characteristics & $\mathrm{Y}$ & Y & Y & Y & $\mathrm{Y}$ & $\mathrm{Y}$ & Y \\
\hline Observations & 6,794 & 6,794 & 6,794 & 6,794 & 6,794 & 6,794 & 6,794 \\
\hline R-squared & 0.212 & 0.286 & 0.134 & 0.281 & 0.146 & 0.270 & 0.147 \\
\hline
\end{tabular}

Poisson Specification; Robust standard errors in parentheses

$* * * p<0.01, * * p<0.05, * p<0.1$

Table 5B: Applicant Characteristics and Text-Based Score Predictions

The dependent variable is the fitted probability of an ordered-logit regression predicting a proposal score from reviewers, based purely on the words contained in the proposal's title and description, and calibrated using only the proposals of male applicants. Specifically, the outcome variable predicts reviewer scores based on the presence or absence of the 500 frequent words with the greatest impact on reviewer scores, further subdivided across words with a positive impact ("high-scoring") and words with a negative impact ("low-scoring") on reviewer scores in specifications 4 and 5 , and across broad and narrow words (based on the standard deviation of word use across topics) in specifications 6 and 7 .

\begin{tabular}{|c|c|c|c|c|c|c|c|}
\hline \multirow[b]{3}{*}{ VARIABLES } & (1) & (2) & (3) & (4) & (5) & (6) & (7) \\
\hline & \multicolumn{7}{|c|}{ DV $=$ Text-Based Reviewer Score Prediction } \\
\hline & \multicolumn{3}{|c|}{ Basis: All Frequent Words } & $\begin{array}{c}\text { Basis: High- } \\
\text { Scoring Words }\end{array}$ & $\begin{array}{c}\text { Basis: Low- } \\
\text { Scoring Words }\end{array}$ & $\begin{array}{c}\text { Basis: Broad } \\
\text { Words }\end{array}$ & $\begin{array}{c}\text { Basis: Narrow } \\
\text { Words }\end{array}$ \\
\hline Female Applicant & $\begin{array}{c}-0.139 * * * \\
(0.029)\end{array}$ & $\begin{array}{c}-0.116^{* * *} \\
(0.029)\end{array}$ & $\begin{array}{c}-0.106^{* * *} \\
(0.029)\end{array}$ & $\begin{array}{c}-0.095^{* * *} \\
(0.029)\end{array}$ & $\begin{array}{c}-0.084 * * * \\
(0.029)\end{array}$ & $\begin{array}{c}-0.060 * * \\
(0.029)\end{array}$ & $\begin{array}{c}-0.155^{* * *} \\
(0.032)\end{array}$ \\
\hline Log(Frequent Word Count) & & $\begin{array}{c}-0.335 * * * \\
(0.044)\end{array}$ & $\begin{array}{c}-0.337^{* * *} \\
(0.044)\end{array}$ & $\begin{array}{c}-0.359 * * * \\
(0.045)\end{array}$ & $\begin{array}{c}-0.419 * * * \\
(0.044)\end{array}$ & $\begin{array}{l}-0.076^{*} \\
(0.044)\end{array}$ & $\begin{array}{c}0.532 * * * \\
(0.047)\end{array}$ \\
\hline Noun Share & & $\begin{array}{l}-0.277^{*} \\
(0.155)\end{array}$ & $\begin{array}{l}-0.266^{*} \\
(0.155)\end{array}$ & $\begin{array}{l}-0.221 \\
(0.149)\end{array}$ & $\begin{array}{c}-0.316^{* *} \\
(0.153)\end{array}$ & $\begin{array}{l}-0.199 \\
(0.166)\end{array}$ & $\begin{array}{c}0.065 \\
(0.200)\end{array}$ \\
\hline Adjective Share & & $\begin{array}{c}0.540 * * * \\
(0.168)\end{array}$ & $\begin{array}{c}0.533^{* * *} \\
(0.168)\end{array}$ & $\begin{array}{c}0.371 * * \\
(0.162)\end{array}$ & $\begin{array}{c}0.456 * * * \\
(0.166)\end{array}$ & $\begin{array}{c}0.437^{* *} \\
(0.180)\end{array}$ & $\begin{array}{c}0.472 * * \\
(0.199)\end{array}$ \\
\hline Verb Share & & $\begin{array}{c}0.166 \\
(0.199)\end{array}$ & $\begin{array}{c}0.166 \\
(0.199)\end{array}$ & $\begin{array}{c}0.250 \\
(0.191)\end{array}$ & $\begin{array}{c}0.181 \\
(0.197)\end{array}$ & $\begin{array}{c}-0.098 \\
(0.216)\end{array}$ & $\begin{array}{l}-0.199 \\
(0.254)\end{array}$ \\
\hline Proposal Text Grade Level & & $\begin{array}{l}-0.007 \\
(0.005)\end{array}$ & $\begin{array}{l}-0.007 \\
(0.005)\end{array}$ & $\begin{array}{c}0.002 \\
(0.006)\end{array}$ & $\begin{array}{l}-0.009 * \\
(0.005)\end{array}$ & $\begin{array}{c}-0.016^{* * *} \\
(0.005)\end{array}$ & $\begin{array}{c}0.001 \\
(0.005)\end{array}$ \\
\hline Log(Applicant Career Length) & & & $\begin{array}{c}0.018 \\
(0.019)\end{array}$ & $\begin{array}{l}0.034^{*} \\
(0.018)\end{array}$ & $\begin{array}{c}0.022 \\
(0.019)\end{array}$ & $\begin{array}{l}-0.016 \\
(0.020)\end{array}$ & $\begin{array}{l}-0.027 \\
(0.017)\end{array}$ \\
\hline Share of Top-Journal Pubs & & & $\begin{array}{c}0.054 \\
(0.056)\end{array}$ & $\begin{array}{l}-0.043 \\
(0.057)\end{array}$ & $\begin{array}{c}0.049 \\
(0.055)\end{array}$ & $\begin{array}{c}0.163^{* * *} \\
(0.056)\end{array}$ & $\begin{array}{c}0.036 \\
(0.061)\end{array}$ \\
\hline Round FEs & $\mathrm{Y}$ & Y & Y & Y & Y & Y & Y \\
\hline Topic Area FEs & $\mathrm{N}$ & Y & Y & Y & Y & Y & Y \\
\hline Additional Text-Based Controls & $\mathrm{N}$ & Y & Y & Y & Y & Y & Y \\
\hline Additional Publication Characteristics & $\mathrm{N}$ & $\mathrm{N}$ & Y & Y & Y & Y & Y \\
\hline Observations & 6,794 & 6,794 & 6,794 & 6,794 & 6,794 & 6,794 & 6,794 \\
\hline R-squared & 0.069 & 0.094 & 0.095 & 0.121 & 0.104 & 0.018 & 0.086 \\
\hline
\end{tabular}

OLS Specification; Robust standard errors in parentheses

*** $p<0.01, * * p<0.05, * p<0.1$ 
Table 5C: Impact of Proposal Text on Reviewer Scores

This table takes the outcome variables for "broad" and "narrow" words from Table 5A and uses them to predict reviewer scores alongside the effect of being a female applicant. Importantly, the text-based score predictions are calibrated based only on proposals from male applicants, and then calculated for all proposals based on the presence or absence of the 500 frequent words with the greatest impact on reviewer scores in each proposal's title and description, sub-divided into broad and narrow words based on the standard deviation of word use rates across topics.

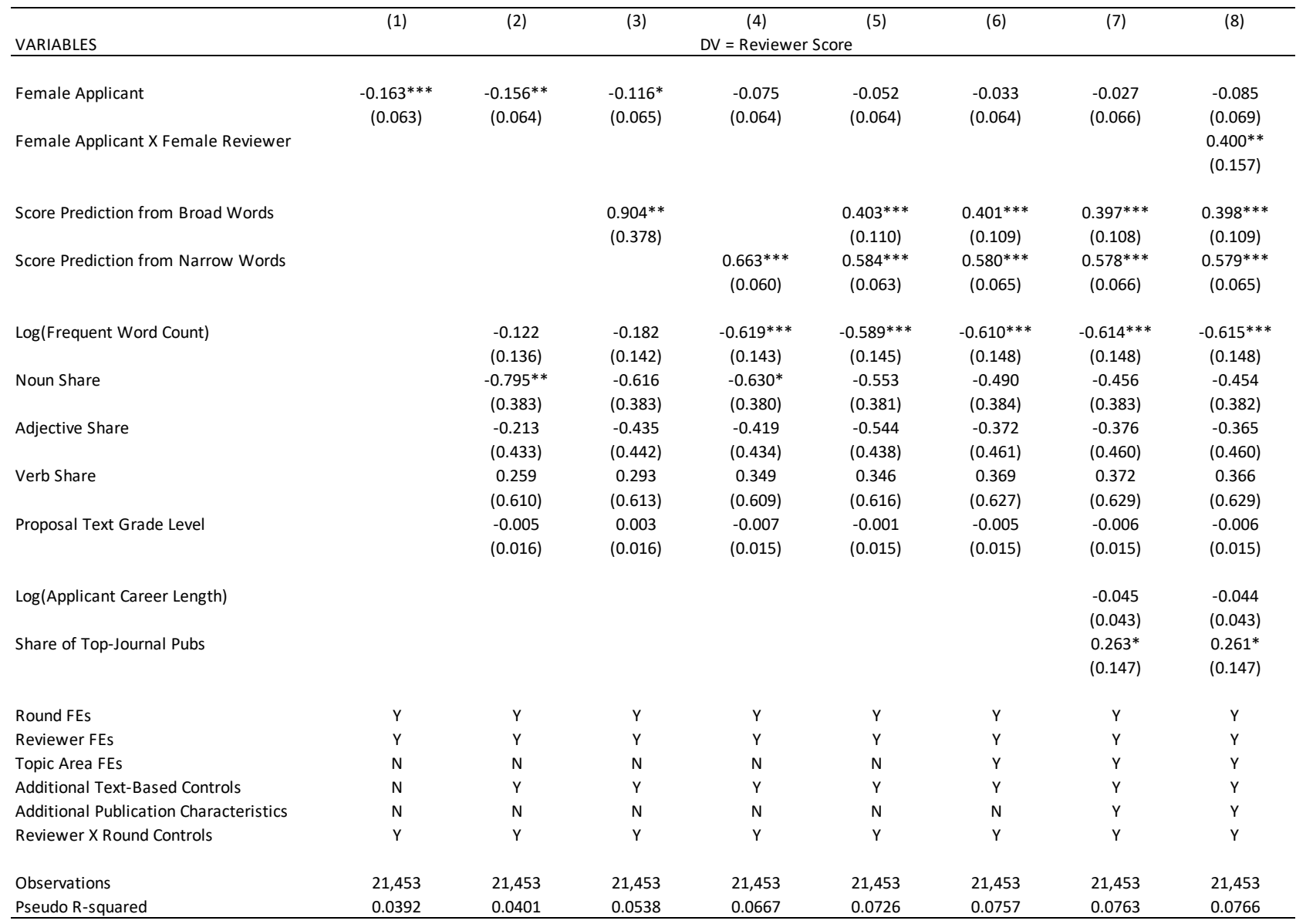

Ordered logit specification; Robust standard errors clustered by reviewer in parentheses

$* * * p<0.01, * * p<0.05, * p<0.1$ 
Table 6: Combined Effects of All Explanatory Variables on Reviewer Scores

\begin{tabular}{|c|c|c|c|c|c|c|c|}
\hline \multirow[b]{2}{*}{ VARIABLES } & (1) & (2) & (3) & (4) & (5) & (6) & (7) \\
\hline & \multicolumn{7}{|c|}{ DV = Reviewer Score } \\
\hline Female Applicant & $\begin{array}{c}-0.163^{* * *} \\
(0.063)\end{array}$ & $\begin{array}{c}-0.214^{* * *} \\
(0.069)\end{array}$ & $\begin{array}{c}-0.194^{* * *} \\
(0.071)\end{array}$ & $\begin{array}{c}-0.186^{* * *} \\
(0.070)\end{array}$ & $\begin{array}{c}-0.180 * * \\
(0.070)\end{array}$ & $\begin{array}{c}-0.173^{* *} \\
(0.070)\end{array}$ & $\begin{array}{c}-0.076 \\
(0.069)\end{array}$ \\
\hline Female Applicant X Female Reviewer & & $\begin{array}{c}0.348^{* *} \\
(0.143)\end{array}$ & $\begin{array}{c}0.364^{* * *} \\
(0.138)\end{array}$ & $\begin{array}{c}0.357^{* *} \\
(0.139)\end{array}$ & $\begin{array}{c}0.358^{* *} \\
(0.139)\end{array}$ & $\begin{array}{c}0.358^{* *} \\
(0.140)\end{array}$ & $\begin{array}{c}0.398 * * \\
(0.157)\end{array}$ \\
\hline Repeat Applicant After Rejection & & & & & $\begin{array}{c}0.256^{* * *} \\
(0.064)\end{array}$ & $\begin{array}{c}0.257^{* * *} \\
(0.064)\end{array}$ & $\begin{array}{c}0.259 * * * \\
(0.063)\end{array}$ \\
\hline Log(Frequent Word Count) & & & & & & $\begin{array}{l}-0.136 \\
(0.141)\end{array}$ & $\begin{array}{c}-0.618^{* * *} \\
(0.149)\end{array}$ \\
\hline Noun Share & & & & & & $\begin{array}{l}-0.711^{*} \\
(0.384)\end{array}$ & $\begin{array}{c}-0.447 \\
(0.380)\end{array}$ \\
\hline Adjective Share & & & & & & $\begin{array}{l}-0.006 \\
(0.451)\end{array}$ & $\begin{array}{c}-0.322 \\
(0.457)\end{array}$ \\
\hline Verb Share & & & & & & $\begin{array}{c}0.322 \\
(0.613)\end{array}$ & $\begin{array}{c}0.434 \\
(0.624)\end{array}$ \\
\hline Proposal Text Grade Level & & & & & & $\begin{array}{c}-0.012 \\
(0.016)\end{array}$ & $\begin{array}{l}-0.006 \\
(0.015)\end{array}$ \\
\hline Score Prediction from Broad Words & & & & & & & $\begin{array}{c}0.397^{* * *} \\
(0.108)\end{array}$ \\
\hline Score Prediction from Narrow Words & & & & & & & $\begin{array}{c}0.580 * * * \\
(0.066)\end{array}$ \\
\hline Log(Applicant Career Length) & & & & $\begin{array}{l}-0.066 \\
(0.042)\end{array}$ & $\begin{array}{c}-0.078 * \\
(0.042)\end{array}$ & $\begin{array}{c}-0.078 * \\
(0.042)\end{array}$ & $\begin{array}{l}-0.055 \\
(0.043)\end{array}$ \\
\hline Log(Pre-Period Publications) & & & & $\begin{array}{c}0.062 \\
(0.046)\end{array}$ & $\begin{array}{c}0.062 \\
(0.046)\end{array}$ & $\begin{array}{c}0.058 \\
(0.046)\end{array}$ & $\begin{array}{c}0.032 \\
(0.048)\end{array}$ \\
\hline Share of Top-Journal Pubs & & & & $\begin{array}{l}0.342^{* *} \\
(0.139)\end{array}$ & $\begin{array}{c}0.348 * * \\
(0.139)\end{array}$ & $\begin{array}{c}0.347^{* *} \\
(0.139)\end{array}$ & $\begin{array}{l}0.259^{*} \\
(0.147)\end{array}$ \\
\hline Share of Last-Author Pubs & & & & $\begin{array}{c}0.092 \\
(0.115)\end{array}$ & $\begin{array}{c}0.091 \\
(0.115)\end{array}$ & $\begin{array}{c}0.096 \\
(0.115)\end{array}$ & $\begin{array}{c}0.127 \\
(0.116)\end{array}$ \\
\hline Round FEs & Y & $\mathrm{Y}$ & Y & Y & $\mathrm{Y}$ & Y & $\mathrm{Y}$ \\
\hline Reviewer FEs & Y & Y & Y & $\mathrm{Y}$ & $\mathrm{Y}$ & Y & $\mathrm{Y}$ \\
\hline Topic Area FEs & $\mathrm{N}$ & $\mathrm{N}$ & Y & $\mathrm{Y}$ & $\mathrm{Y}$ & Y & $\mathrm{Y}$ \\
\hline Additional Text-Based Controls & $\mathrm{N}$ & $\mathrm{N}$ & $\mathrm{N}$ & $\mathrm{N}$ & $\mathrm{N}$ & Y & $\mathrm{Y}$ \\
\hline Reviewer X Round Controls & Y & $\mathrm{Y}$ & Y & $\mathrm{Y}$ & $\mathrm{Y}$ & Y & $\mathrm{Y}$ \\
\hline Observations & 21,453 & 21,453 & 21,453 & 21,453 & 21,453 & 21,453 & 21,453 \\
\hline Pseudo R-squared & 0.0392 & 0.0395 & 0.0435 & 0.0445 & 0.0458 & 0.0466 & 0.0779 \\
\hline
\end{tabular}

Ordered logit specification; Robust standard errors clustered by reviewer in parentheses

*** $p<0.01, * * p<0.05, * p<0.1$ 
Table 7: Impact of Applicant Gender on Post-Period Outcomes

\begin{tabular}{|c|c|c|c|c|c|c|c|c|c|}
\hline VARIABLES & $\begin{array}{c}\text { (1) } \\
\text { Phase } 2 \\
\text { Applications }\end{array}$ & $\begin{array}{c}\text { (2) } \\
\text { Phase } 2 \\
\text { Successes }\end{array}$ & Article Count & $\begin{array}{c}\text { (4) } \\
\text { Top-Journal } \\
\text { Article Count }\end{array}$ & $\begin{array}{c}\text { (5) } \\
\text { New Journal } \\
\text { Count }\end{array}$ & $\begin{array}{c}\text { (6) } \\
\text { New } \\
\text { Coauthor } \\
\text { Count }\end{array}$ & $\begin{array}{c}\text { (7) } \\
\text { New MeSH } \\
\text { Count }\end{array}$ & $\begin{array}{c}\text { (8) } \\
\text { NIH Grant } \\
\text { Count }\end{array}$ & $\begin{array}{c}\text { (9) } \\
\text { NIH R01 } \\
\text { Count }\end{array}$ \\
\hline Female Applicant & $\begin{array}{l}-0.022 \\
(0.104)\end{array}$ & $\begin{array}{l}-0.109 \\
(0.511)\end{array}$ & $\begin{array}{c}0.011 \\
(0.082)\end{array}$ & $\begin{array}{l}-0.009 \\
(0.145)\end{array}$ & $\begin{array}{c}0.001 \\
(0.116)\end{array}$ & $\begin{array}{c}0.010 \\
(0.112)\end{array}$ & $\begin{array}{c}-0.014 \\
(0.108)\end{array}$ & $\begin{array}{l}0.373 * \\
(0.218)\end{array}$ & $\begin{array}{c}0.339 \\
(0.303)\end{array}$ \\
\hline Average Proposal Score & $\begin{array}{c}0.010 \\
(0.206)\end{array}$ & $\begin{array}{c}1.294 \\
(1.069)\end{array}$ & $\begin{array}{l}-0.090 \\
(0.201)\end{array}$ & $\begin{array}{l}-0.210 \\
(0.342)\end{array}$ & $\begin{array}{c}-0.070 \\
(0.281)\end{array}$ & $\begin{array}{c}0.111 \\
(0.316)\end{array}$ & $\begin{array}{c}-0.034 \\
(0.229)\end{array}$ & $\begin{array}{c}0.749 \\
(0.493)\end{array}$ & $\begin{array}{l}-0.157 \\
(1.128)\end{array}$ \\
\hline Score Prediction from Broad Words & $\begin{array}{c}0.030 \\
(0.049)\end{array}$ & $\begin{array}{l}-0.214 \\
(0.234)\end{array}$ & $\begin{array}{c}0.015 \\
(0.038)\end{array}$ & $\begin{array}{c}-0.128^{* *} \\
(0.063)\end{array}$ & $\begin{array}{c}0.050 \\
(0.047)\end{array}$ & $\begin{array}{c}-0.187^{* *} \\
(0.080)\end{array}$ & $\begin{array}{c}0.016 \\
(0.041)\end{array}$ & $\begin{array}{c}-0.223 * * * \\
(0.075)\end{array}$ & $\begin{array}{c}-0.261^{* *} \\
(0.118)\end{array}$ \\
\hline Score Prediction from Narrow Words & $\begin{array}{c}0.006 \\
(0.020)\end{array}$ & $\begin{array}{l}-0.026 \\
(0.122)\end{array}$ & $\begin{array}{c}0.021 \\
(0.014)\end{array}$ & $\begin{array}{c}0.038 \\
(0.030)\end{array}$ & $\begin{array}{l}-0.009 \\
(0.018)\end{array}$ & $\begin{array}{l}0.037^{*} \\
(0.021)\end{array}$ & $\begin{array}{c}0.012 \\
(0.022)\end{array}$ & $\begin{array}{c}-0.074 * * * \\
(0.027)\end{array}$ & $\begin{array}{c}0.046 \\
(0.058)\end{array}$ \\
\hline Proposal Text Grade Level & $\begin{array}{c}0.009 \\
(0.010)\end{array}$ & $\begin{array}{c}0.020 \\
(0.042)\end{array}$ & $\begin{array}{l}0.015^{*} \\
(0.008)\end{array}$ & $\begin{array}{c}0.030 * * \\
(0.014)\end{array}$ & $\begin{array}{c}0.023 * * \\
(0.011)\end{array}$ & $\begin{array}{c}0.015 \\
(0.012)\end{array}$ & $\begin{array}{l}0.018 * \\
(0.010)\end{array}$ & $\begin{array}{c}0.038 \\
(0.026)\end{array}$ & $\begin{array}{c}0.015 \\
(0.031)\end{array}$ \\
\hline Pre-Period Article Count & $\begin{array}{c}0.036 \\
(0.045)\end{array}$ & $\begin{array}{c}0.178 \\
(0.172)\end{array}$ & $\begin{array}{c}0.836 * * * \\
(0.043)\end{array}$ & $\begin{array}{c}0.383^{* * *} \\
(0.102)\end{array}$ & $\begin{array}{c}0.164^{*} \\
(0.099)\end{array}$ & $\begin{array}{c}0.229 * * \\
(0.093)\end{array}$ & $\begin{array}{c}0.320 * * * \\
(0.092)\end{array}$ & $\begin{array}{c}0.367^{* * *} \\
(0.132)\end{array}$ & $\begin{array}{c}0.676 * * * \\
(0.162)\end{array}$ \\
\hline Pre-Period Focal Outcome & & & & $\begin{array}{c}0.584 * * * \\
(0.089)\end{array}$ & $\begin{array}{c}0.458 * * * \\
(0.115)\end{array}$ & $\begin{array}{c}0.561^{* * *} \\
(0.069)\end{array}$ & $\begin{array}{c}0.331 * * * \\
(0.083)\end{array}$ & $\begin{array}{c}0.719 * * * \\
(0.141)\end{array}$ & $\begin{array}{c}0.742 * * * \\
(0.285)\end{array}$ \\
\hline Additional Controls: & & & & & & & & & \\
\hline Round FEs & Y & Y & Y & Y & Y & Y & Y & Y & Y \\
\hline Topic Area FEs & $\mathrm{Y}$ & $\mathrm{Y}$ & $\mathrm{Y}$ & $\mathrm{Y}$ & Y & $\mathrm{Y}$ & $\mathrm{Y}$ & Y & $\mathrm{Y}$ \\
\hline Applicant Career Length FEs & $\mathrm{Y}$ & $\mathrm{Y}$ & Y & $\mathrm{Y}$ & Y & $\mathrm{Y}$ & $\mathrm{Y}$ & Y & Y \\
\hline Sample of Applicants: & $\begin{array}{c}\text { Funded \& } \\
\text { Active }\end{array}$ & $\begin{array}{c}\text { Funded \& } \\
\text { Active }\end{array}$ & $\begin{array}{c}\text { Funded \& } \\
\text { Active }\end{array}$ & $\begin{array}{c}\text { Funded \& } \\
\text { Active }\end{array}$ & $\begin{array}{c}\text { Funded \& } \\
\text { Active }\end{array}$ & $\begin{array}{c}\text { Funded \& } \\
\text { Active }\end{array}$ & $\begin{array}{c}\text { Funded \& } \\
\text { Active }\end{array}$ & $\begin{array}{c}\text { Funded \& } \\
\text { Active }\end{array}$ & $\begin{array}{c}\text { Funded \& } \\
\text { Active }\end{array}$ \\
\hline Observations & 500 & 500 & 500 & 500 & 500 & 500 & 500 & 500 & 500 \\
\hline Pseudo R-squared & 0.0525 & 0.368 & 0.476 & 0.337 & 0.225 & 0.628 & 0.490 & 0.377 & 0.350 \\
\hline
\end{tabular}

Poisson specification; Robust standard errors clustered by applicant in parentheses

$* * * p<0.01, * * p<0.05, * p<0.1$ 
Table 8: Effectiveness of Funding by Applicant Gender

\begin{tabular}{|c|c|c|c|c|c|c|c|}
\hline VARIABLES & Article Count & $\begin{array}{c}\text { (2) } \\
\text { Top-Journal } \\
\text { Article Count }\end{array}$ & $\begin{array}{c}\text { (3) } \\
\text { New Journal } \\
\text { Count }\end{array}$ & $\begin{array}{c}\text { (4) } \\
\text { New } \\
\text { Coauthor } \\
\text { Count } \\
\end{array}$ & $\begin{array}{c}\text { (5) } \\
\text { New MeSH } \\
\text { Count }\end{array}$ & $\begin{array}{c}(6) \\
\text { NIH Grant } \\
\text { Count }\end{array}$ & $\begin{array}{c}(7) \\
\text { NIH R01 } \\
\text { Count }\end{array}$ \\
\hline Female Applicant & $\begin{array}{l}-0.086 \\
(0.067)\end{array}$ & $\begin{array}{c}-0.265^{* *} \\
(0.113)\end{array}$ & $\begin{array}{c}-0.200^{* *} \\
(0.092)\end{array}$ & $\begin{array}{c}-0.259 * * \\
(0.102)\end{array}$ & $\begin{array}{c}-0.199 * * \\
(0.087)\end{array}$ & $\begin{array}{l}-0.022 \\
(0.182)\end{array}$ & $\begin{array}{l}-0.208 \\
(0.252)\end{array}$ \\
\hline Female Applicant X Funding & $\begin{array}{c}0.195 * * \\
(0.095)\end{array}$ & $\begin{array}{l}0.404^{* *} \\
(0.160)\end{array}$ & $\begin{array}{c}0.378 * * * \\
(0.131)\end{array}$ & $\begin{array}{c}0.376 * * * \\
(0.134)\end{array}$ & $\begin{array}{l}0.302^{* *} \\
(0.133)\end{array}$ & $\begin{array}{l}0.411^{*} \\
(0.237)\end{array}$ & $\begin{array}{c}0.868 * * \\
(0.397)\end{array}$ \\
\hline Funding Indicator & $\begin{array}{c}0.053 \\
(0.054)\end{array}$ & $\begin{array}{c}0.139 \\
(0.093)\end{array}$ & $\begin{array}{l}-0.032 \\
(0.074)\end{array}$ & $\begin{array}{c}0.187^{* *} \\
(0.085)\end{array}$ & $\begin{array}{c}0.067 \\
(0.067)\end{array}$ & $\begin{array}{c}0.113 \\
(0.161)\end{array}$ & $\begin{array}{l}-0.143 \\
(0.262)\end{array}$ \\
\hline Average Proposal Score & $\begin{array}{l}-0.113 \\
(0.233)\end{array}$ & $\begin{array}{l}-0.659 \\
(0.436)\end{array}$ & $\begin{array}{c}0.104 \\
(0.356)\end{array}$ & $\begin{array}{l}-0.223 \\
(0.345)\end{array}$ & $\begin{array}{l}-0.132 \\
(0.271)\end{array}$ & $\begin{array}{l}-0.508 \\
(0.512)\end{array}$ & $\begin{array}{l}-1.265 \\
(1.160)\end{array}$ \\
\hline Score Prediction from Broad Words & $\begin{array}{c}0.030 \\
(0.031)\end{array}$ & $\begin{array}{l}-0.028 \\
(0.043)\end{array}$ & $\begin{array}{c}0.033 \\
(0.034)\end{array}$ & $\begin{array}{l}-0.035 \\
(0.082)\end{array}$ & $\begin{array}{c}0.054 \\
(0.040)\end{array}$ & $\begin{array}{c}-0.171^{* * *} \\
(0.064)\end{array}$ & $\begin{array}{l}-0.143^{*} \\
(0.087)\end{array}$ \\
\hline Score Prediction from Narrow Words & $\begin{array}{c}0.007 \\
(0.013)\end{array}$ & $\begin{array}{c}0.034 \\
(0.022)\end{array}$ & $\begin{array}{c}0.001 \\
(0.018)\end{array}$ & $\begin{array}{c}0.018 \\
(0.021)\end{array}$ & $\begin{array}{c}0.004 \\
(0.015)\end{array}$ & $\begin{array}{c}-0.020 \\
(0.025)\end{array}$ & $\begin{array}{c}0.018 \\
(0.031)\end{array}$ \\
\hline Proposal Text Grade Level & $\begin{array}{l}0.015 * * \\
(0.006)\end{array}$ & $\begin{array}{c}0.029 * * * \\
(0.010)\end{array}$ & $\begin{array}{c}0.020 * * \\
(0.008)\end{array}$ & $\begin{array}{l}0.021 * * \\
(0.010)\end{array}$ & $\begin{array}{c}0.022 * * * \\
(0.008)\end{array}$ & $\begin{array}{l}0.038 * * \\
(0.019)\end{array}$ & $\begin{array}{c}0.024 \\
(0.026)\end{array}$ \\
\hline Pre-Period Article Count & $\begin{array}{c}0.841 * * * \\
(0.027)\end{array}$ & $\begin{array}{c}0.532 * * * \\
(0.071)\end{array}$ & $\begin{array}{c}0.217^{* * *} \\
(0.065)\end{array}$ & $\begin{array}{c}0.240 * * * \\
(0.059)\end{array}$ & $\begin{array}{c}0.309 * * * \\
(0.064)\end{array}$ & $\begin{array}{c}0.423 * * * \\
(0.086)\end{array}$ & $\begin{array}{c}0.475 * * * \\
(0.121)\end{array}$ \\
\hline Pre-Period Focal Outcome & & $\begin{array}{c}0.435 * * * \\
(0.069)\end{array}$ & $\begin{array}{c}0.426 * * * \\
(0.084)\end{array}$ & $\begin{array}{c}0.480 * * * \\
(0.042)\end{array}$ & $\begin{array}{c}0.341 * * * \\
(0.064)\end{array}$ & $\begin{array}{c}0.878 * * * \\
(0.102)\end{array}$ & $\begin{array}{c}1.561 * * * \\
(0.218)\end{array}$ \\
\hline Additional Controls: & & & & & & & \\
\hline Round FEs & Y & Y & Y & Y & Y & Y & Y \\
\hline Topic Area FEs & Y & Y & Y & Y & Y & Y & Y \\
\hline Applicant Career Length FEs & Y & Y & Y & Y & Y & Y & Y \\
\hline Pre-Period Applicant Characteristics & Y & Y & Y & Y & Y & Y & $\mathrm{Y}$ \\
\hline Sample of Applicants: & $\begin{array}{l}\text { High-Scoring } \\
\text { \& Active }\end{array}$ & $\begin{array}{l}\text { High-Scoring } \\
\text { \& Active }\end{array}$ & $\begin{array}{l}\text { High-Scoring } \\
\text { \& Active }\end{array}$ & $\begin{array}{l}\text { High-Scoring } \\
\text { \& Active }\end{array}$ & $\begin{array}{c}\text { High-Scoring } \\
\text { \& Active }\end{array}$ & $\begin{array}{l}\text { High-Scoring } \\
\text { \& Active }\end{array}$ & $\begin{array}{l}\text { High-Scoring } \\
\text { \& Active }\end{array}$ \\
\hline Observations & 1,163 & 1,163 & 1,163 & 1,163 & 1,163 & 1,163 & 1,163 \\
\hline Pseudo R-squared & 0.438 & 0.282 & 0.178 & 0.509 & 0.407 & 0.274 & 0.283 \\
\hline
\end{tabular}

Poisson specification; Robust standard errors clustered by applicant in parentheses

*** $p<0.01, * * p<0.05, * p<0.1$ 